\title{
Secretome of Intestinal Bacilli: A Natural Guard against Pathologies
}

\author{
Olga N. Ilinskaya ${ }^{1 *}$, Vera V. Ulyanova ${ }^{1}$, Dina R. Yarullina ${ }^{1}$ and Ilgiz G. Gataullin ${ }^{2}$ \\ 'Department of Microbiology, Kazan Federal University, Kazan, Russia, ${ }^{2}$ Department of Surgery and Oncology, Regional \\ Clinical Cancer Center, Kazan, Russia
}

Current studies of human gut microbiome usually do not consider the special functional role of transient microbiota, although some of its members remain in the host for a long time and produce broad spectrum of biologically active substances. Getting into the gastrointestinal tract (GIT) with food, water and probiotic preparations, two representatives of Bacilli class, genera Bacillus and Lactobacillus, colonize epithelium blurring the boundaries between resident and transient microbiota. Despite their minor proportion in the microbiome composition, these bacteria can significantly affect both the intestinal microbiota and the entire body thanks to a wide range of secreted compounds. Recently, insufficiency and limitations of pure genome-based analysis of

OPEN ACCESS

Edited by:

Wesley H. Brooks, University of South Florida,

United States

Reviewed by:

Marisa Mariel Fernandez, Instituto de Estudios de la Inmunidad Humoral (CONICET-UBA), Argentina Andrey Tatarenkov, University of California, Irvine, United States

*Correspondence: Olga N. llinskaya ilinskaya_kfu@mail.ru

Specialty section:

This article was submitted to Microbial Immunology, a section of the journal Frontiers in Microbiology

Received: 25 July 2017

Accepted: 17 August 2017 Published: 01 September 2017

Citation:

llinskaya ON, Ulyanova W, Yarullina DR and Gataullin IG (2017) Secretome of Intestinal Bacilli: A Natural Guard against Pathologies.

Front. Microbiol. 8:1666. doi: 10.3389/fmicb.2017.01666 gut microbiota became known. Thus, the need for intense functional studies is evident. This review aims to characterize the Bacillus and Lactobacillus in GIT, as well as the functional roles of the components released by these members of microbial intestinal community. Complex of their secreted compounds is referred by us as the "bacillary secretome." The composition of the bacillary secretome, its biological effects in GIT and role in counteraction to infectious diseases and oncological pathologies in human organism is the subject of the review.

Keywords: Lactobacillus, Bacillus, gastrointestinal tract, metabolites, secretome

\section{INTRODUCTION}

The human gut microbiota consists of about 1500 microbial species which constitute $10^{12}$ bacteria per gram of stool (Browne et al., 2016). The gastrointestinal microbiota of healthy human adults consists primarily of bacteria belonging to phyla Firmicutes and Bacteroidetes, and to a lesser extent to phyla Actinobacteria and Proteobacteria (Dethlefsen et al., 2008; Yang and Jobin, 2014). Density and composition of microbiota varies along both the length of the gut and the cross-section (Nava and Stappenbeck, 2011; Tropini et al., 2017). Changes in nutrients, availability of oxygen, and presence of immune effectors in local microenvironment determine species variation and abundance (Donaldson et al., 2016). The most dominant taxa have the highest stability in the gut (Martí et al., 2017). Rapidly dividing facultative anaerobes from Lactobacillaceae and Enterobacteriaceae dominate in small intestine, while saccharolytic representatives of Bacteroidales and Clostridiales orders are abundant in the large intestine (Donaldson et al., 2016; Tropini et al., 2017). Mucin-utilizing species of Akkermansia and Bacteroides are followed by aerotolerant Proteobacteria and Actinobacteria in direction to the

Abbreviations: CSF, competence and sporulation factor; EVs, extracellular vesicles; GIT, gastrointestinal tract; NO, nitric oxide; NOS, nitric oxide synthase; RNases, ribonucleases; SCFAs, short-chain fatty acids. 
epithelium (Tropini et al., 2017). Proteobacteria and Firmicutes are found in crypts and represent the stock for reseeding the colon because they are protected from the luminal flow (Tropini et al., 2017). At least $50-60 \%$ of the bacterial genera from the intestinal microbiota of a healthy individual produce spores which facilitate both microbiota persistence and transmission (Browne et al., 2016). The majority of gut bacteria are transient populations which pass through the lumen of the lower GIT (Tropini et al., 2017).

Composition of gut microbiota varies among individuals with geographic provenance, gender, age, diet, malnutrition, and intake of probiotics or antimicrobial agents (Panda et al., 2014; Haro et al., 2016; Odamaki et al., 2016; Maffei et al., 2017; Martí et al., 2017; Singh et al., 2017). Alterations in the composition of the gut microbiota and reductions in microbial diversity lead to different disorders such as inflammatory conditions of the intestine (inflammatory bowel disease, irritable bowel syndrome, colorectal cancer) (Gagnière et al., 2016; Ghoshal et al., 2017; Rapozo et al., 2017), type 2 diabetes, obesity, anorexia nervosa, forms of severe acute malnutrition, cardiovascular diseases (atherosclerosis, hypertension, heart failure) (Tang et al., 2017), neurobehavioral diseases (autism spectrum disorder, major depression) (Clemente et al., 2012). The microbiota is increasingly recognized for its ability to maintain homeostasis in health and disease influencing host appetite, function of the nervous system and several complex host behaviors (Sharon et al., 2016; Winek et al., 2016; van de Wouw et al., 2017; Vuong et al., 2017). A healthy gut microbiota can be defined by the presence of the various microbial species that enhance metabolism, resistance to infection and inflammation, prevention against cancer and autoimmunity.

Lactobacilli are historically considered as integral part of human intestinal microbiota. Today, a large body of evidence indicates that only a small number of Lactobacillus species are true autochthonous inhabitants of the mammalian intestinal tract and that most lactobacilli present are allochthonous members derived from food or oral cavity (Reuter, 2001; Walter, 2008). Lactobacillus spp. content of fecal samples is characterized by temporal fluctuations and lack of stability (Walter et al., 2001; Vanhoutte et al., 2004). Attempts to divide lactobacilli into resident and transient ones are hardly legitimate since the style of nutrition significantly affects their contents in the intestine. Lactobacilli together with enterococci dominate in the duodenum and in the jejunum (Reuter, 2001; Hammes and Hertel, 2015), although their absolute number increases along the intestine from duodenum to colon (Derrien and van Hylckama Vlieg, 2015). However, they constitute only a minor fraction within the human adult fecal microbiota, i.e., around 0.01 to $0.6 \%$ of total bacterial counts (Harmsen et al., 2002; Matsuda et al., 2009).

Metagenomics widely used for study of gut microbiota is unable to detect bacteria at concentrations less than $10^{5}$ bacteria per gram (Lagier et al., 2015). A culturing approach that uses high-throughput culture conditions in combination with matrix-assisted laser desorption/ionization-time of flight (MALDI-TOF) mass spectrometry and 16S rRNA sequencing for taxonomic identification and referred to as culturomics has allowed significant increase in a number of bacteria discovered in human GIT including species known in humans but not in the gut, species previously considered unculturable as well as new species. Considerable part of them is represented by Firmicutes (Lagier et al., 2016) including Bacillus species (Lagier et al., 2015; Mourembou et al., 2016; Senghor et al., 2017).

For a long time, the representatives of Bacillus genus, unlike the species of Lactobacillus, were not considered as a part of the normal intestinal microbiome. Being isolated from feces, Bacillus spp. as soil microorganisms were considered transient. Recent studies show that they are present in the GIT in the amounts significantly higher than what can be explained by their ingestion with food only. Bacillus spp. (B. pumilus, B. licheniformis, B. clausii, B. subtilis, B. megaterium, $B$. mediterraneensis, $B$. thuringiensis) have been isolated from the healthy human GIT, where they are well-adapted and are more colonizing than transient (Fakhry et al., 2008; Alou et al., 2016; Lopetuso et al., 2016). In environment, the vegetative forms of Bacillus are present usually near decomposing plants and in their rhizosphere. In the soil they exist mainly in the form of spores, which germinate in the digestive tract of humans and animals. Germination of Bacillus spores in the human small intestine and transient colonization should be considered as a part of the life cycle of human-associated Bacillus species (Hong et al., 2009). In the GIT, spores not only germinate but also are formed again from vegetative cells during a time shorter than in the laboratory (Tam et al., 2006; Ghelardi et al., 2015).

Thus, it can be concluded that GIT microbiota including Bacillus and Lactobacillus species undergoes constant dynamic change. In our opinion, distinguishing between the resident and transient intestinal inhabitants is less relevant issue compared to the study of molecular pool released by them. Most of bacteria absorbed in the body can supplement the gastrointestinal microbiome (Derrien and van Hylckama Vlieg, 2015). The challenge of identifying the "spheres of influence" of the transient microbiota in the human body has not been solved, and has not even been formulated, with the exception of some aspects of the pathogen entry into the body. Its bottleneck is the lack of data on the complexes secreted by this microbiota, their components, functions and the interaction between components, namely, the composition and biological role of the secretome.

We consciously narrowed the spectrum of secretome producers observed here to two representatives of the Bacilli class, genera Lactobacillus and Bacillus, due to their wide distribution and high probability of entering the human body. The ingestion of microorganisms occurs with food, water and bacterial probiotics. Facultative aerobic bacilli represent a smaller proportion of the intestinal microbiota than anaerobic bacteria (Rajilić-Stojanović and de Vos, 2014), but they actively influence the microbial community of GIT and also the whole organism thanks to the great diversity of secreted compounds. Our studies of biopsies taken during surgical intervention in patients with diagnosed colorectal cancer revealed the presence of Bacilli closely associated with intestinal epithelium, traditionally considered as transient ones (Siraj et al., 2015). Since secretory components can be studied only in culturable microorganisms, the insufficiency of genomic analysis of intestinal microbiota and the transition to functional analysis became evident (Derrien and 
van Hylckama Vlieg, 2015; Lagier et al., 2015). In this regard, the identification, characterization, and elucidation of the functional role of the components secreted by the minority of the intestinal microbial community, namely representatives of the Bacilli class in GIT, is an actual task. The modern concept of a gut-brain axis (McKay et al., 2017) must be detailed and refined taking into account the spectra of compounds secreted by Bacilli, namely low- and high-molecular components of the secretome and EVs, which affect the whole body and shape human health.

\section{BENEFICIAL EFFECTS OF Lactobacillus AND Bacillus}

Historically, species of Lactobacillus and Bacillus are found in the traditional fermented food products possessing beneficial properties for the intestinal function (Nithya et al., 2012; Satish Kumar et al., 2013; Lee et al., 2016; Sornplang and Piyadeatsoontorn, 2016; Marco et al., 2017) and are widely used as components of commercially available probiotics: DE111 (Deerland Enzymes, United States), Enterogermina (Sanofi Winthrop, Italy), Biosubtyl (Biophar, Vietnam), Biosporin (Biopharma, Russia), BioSpora (Klaire Labs, United States), Blicheni and Zhengchangsheng (Northeast Pharmaceutical Group, China), GanedenBC 30 (Ganeden, United States), Lactobacterin (Microgen, Russia), HOWARU or DR20 (Danisco, United States), Yakult (Yakult, Japan), PCC (Probiomics, Australia). In food industry, lactobacilli are applied as starter cultures in the production of fermented milk products, cheese, sausages, bread, kimchi, pickles, and yogurts, the latter accounting for the largest share of sales (Giraffa et al., 2010; Tamang et al., 2016). The administration of probiotics has been shown to favorably alter the intestinal microbiota balance, enhance intestinal integrity and motility, inhibit the growth of harmful bacteria and increase resistance to infections (Tamang et al., 2016).

As a part of GIT microbiota Bacilli participate in metabolism of dietary components, xenobiotics and drugs helping to maintain intestinal homeostasis and host health (Jandhyala et al., 2015; Rowland et al., 2017). The beneficial effect of probiotics on GIT is mediated by influence on composition, diversity and function of the intestinal microbiota as well as whole human organism. Probiotics suppress pathogenic bacteria and favor beneficial ones via competition for nutrients, especially for shared limited resource like iron, competitive attachment to the epithelium, formation of substrates for growth, production of waste products and antimicrobial compounds, strengthening of the barrier function of the epithelium, and modulation of innate immunity (Thomas and Versalovic, 2010; Bermudez-Brito et al., 2012; Stubbendieck and Straight, 2016). For example, consumption of $B$. coagulans was shown to increase beneficial groups of bacteria in the gut of 65-80 years old humans and production of anti-inflammatory cytokines (Nyangale et al., 2015).

The efficacy of Lactobacillus and Bacillus in the prevention and/or treatment of intestinal diseases such as diarrhea, colitis, irritable bowel syndrome, irritable bowel disease, and colorectal cancer was demonstrated (Camilleri, 2006; Sazawal et al., 2006; Rafter et al., 2007; Pillai and Nelson, 2008; Ghouri et al., 2014; Urgesi et al., 2014; Choi et al., 2015; Matsuoka and Kanai, 2015; Majeed et al., 2016; Zhang et al., 2016). In particular, treatment of colorectal colitis in mice with probiotic $B$. subtilis restored balance in gut microflora: beneficial species of Bifidobacterium, Lactobacillus, and Butyricicoccus spp. were increased, while gut damage-promoting species of Acinetobacter sp., Ruminococcus sp., Clostridium spp., and Veillonella sp. were decreased (Zhang et al., 2016). B. subtilis also retained gut barrier integrity, decreased the endotoxin concentration and reduced gut inflammation (Zhang et al., 2016; Bene et al., 2017). Sporulation of B. subtilis plays a major role in the development of GALT - gut lymphoid tissue associated with the gastrointestinal mucosa - and in the diversity of the primary antibody population ("preimmune" repertoire) in rabbits (Rhee et al., 2004). Bacillus spp. like other strains isolated from human stool were able to bind the human norovirus strains, the cause of acute viral gastroenteritis and foodborne diseases, around the outer cell surfaces and pili structures (Almand et al., 2017). The interaction between virus and bacteria is hypothesized to help the host immune system to better recognize infectious particles.

The ratio between the two major phyla inhabiting the human GIT, Firmicutes and Bacteroidetes, reflects the GIT status during the life and diseases. It is significantly decreased in infants and elderly individuals as compared to adults $(0.4,0.6$, and 10.9, respectively) (Mariat et al., 2009) and lowers upon antibiotic-associated diarrhea, coeliac disease, Crohn's disease, and ulcerative colitis (Ott et al., 2004; Panda et al., 2014; Carding et al., 2015; Quagliariello et al., 2016). A decrease in populations of Ruminococcus and Lactobacillus was observed in a rat model of colorectal cancer (Zhu et al., 2014). Microbial content of the patients with diagnosed colorectal cancer and healthy individuals differed significantly. Firmicutes and Fusobacteria were overrepresented whereas Proteobacteria were under-represented in patients. In addition, Lactococcus and Fusobacterium exhibited a relatively higher abundance while Pseudomonas and EscherichiaShigella were reduced in cancerous tissues compared to adjacent non-cancerous ones (Gao et al., 2015). Bacilli were shown to decrease quantitatively upon type 2 diabetes (Sankar et al., 2015). The possibility of using probiotics in the therapy of diseases, namely allergy, asthma, diabetes, cardiovascular diseases is discussed (Ebel et al., 2014).

Viability is by definition a prerequisite for probiotic effectiveness as it is essential for colonization of intestinal mucosa, displacement of pathogens and immunomodulation. Viable bacteria demonstrate adhesive and antagonistic properties and produce a large number of extracellular enzymes and biologically active compounds (Shobharani and Halami, 2014). Nevertheless, there is increasing evidence that isolated bacteriaderived molecules and surface components (e.g., cell wall components, cell wall associated proteins, S-layer proteins) potentiate probiotic benefits attributed earlier to viable probiotic bacteria (Lahtinen, 2012; Ruiz et al., 2014).

Despite more than a century of active use of probiotics, initiated by I. Mechnikov in 1907, the majority of modern reviews assessing the effectiveness of these drugs confirm the need for 
further studies to determine the exact mechanisms of positive effects of probiotics on the human body. Both live probiotic bacterial cells and their metabolites can be useful in treatment of intestinal diseases (Okamoto et al., 2012). The molecular basis for the effectiveness of probiotics remains unexplored or only partially studied. The future study aimed at deciphering the mechanisms that determine the probiotic properties of bacteria will certainly allow expanding the areas of scientifically proven probiotic use in medicine.

\section{MICROBIOTA-HUMAN METABOLIC INTERACTION}

Between the gut microbiota and host organism there is an extremely complex relationship that affects the human metabolism, immunity and health (Marchesi et al., 2016). This crosstalk is mediated by nutrients, metabolites, antimicrobial compounds. It was demonstrated that the psychological and physical stress of a host affects its gut microbiota and, in turn, gut microflora can modulate host's mood and appetite (Sandrini et al., 2015). Gut microbiota is regulated by the host through production of non-specific antimicrobial peptides such as defensins (Nakamura et al., 2016), secreted IgA which provides the selection and the maintenance of the commensal bacteria (Fransen et al., 2015), and miRNAs specifically regulating bacterial transcripts and affecting bacterial growth (Liu and Weiner, 2016). It was proved that host genetic background affects the composition and function of the gut microbiota, altering the production of microbial metabolites and intestinal inflammation (Lamas et al., 2016). For example, the microbiota of mice deficient in caspase recruitment domain family member 9 (CARD9) failed to metabolize tryptophan that increased host susceptibility to colitis (Lamas et al., 2016).

Microbial species are recognized by host's immune system. Commensal bacteria have immunomodulatory properties that allow them inducing tolerogenic immune responses against themselves and contributing to host protective immune responses against pathogens (Bene et al., 2017; Guo et al., 2017; Shi et al., 2017). It is known that probiotics affect key signaling pathways, such as $\mathrm{NF \kappa B}$ and MAPK, through the pattern-recognition receptors (TLR, NOD) (Bermudez-Brito et al., 2012) enhancing the production of anti-inflammatory cytokines (Nyangale et al., 2015) and reducing the emergence of proinflammatory ones (Selvam et al., 2009). The gut microbiota is able to influence host antigen production by human monocytederived dendritic cell populations in a species-specific manner (Bene et al., 2017).

Gut microbiota affects host physiology by releasing bioactive metabolites including antibiotics, enzymes, vitamins and amino acids (choline, methionine, vitamin B), minerals (cobalt, iodine, selenium, and zinc) and energy metabolites (SAM, acetyl-CoA, $\mathrm{NAD}^{+}, \alpha-\mathrm{KG}$, and ATP), SCFAs (acetate, propionate, butyrate, caproate, and valerate), neurotransmitters [acetylcholine, dopamine, noradrenaline, serotonin, and $\gamma$-aminobutyric acid (GABA)], hormones, bacterial antigens, pathogen-associated molecular patterns, and toxins (Donia et al., 2014; Luber and
Kostic, 2017). These molecules enter host circulation thereby mediating the link between the gut and other organs (brain, lung, liver, muscle) (Shukla et al., 2017) and modulate physiological pathways and even behavior (van de Wouw et al., 2017; Vuong et al., 2017). The influence of gut microbiota on the epigenetic regulation of host genes via DNA methylation and histone modifications has been demonstrated (Ye et al., 2017). Contactindependent metabolic exchange helps signal dispersal among neighboring cells as well as its blockage when needed.

Bacteria produce a lot of chemically diverse metabolites with poorly understood function. Bacillus species are among the most frequent producers of bioactive secondary metabolites (800 compounds), while lactobacilli produce 100s of compounds (Bérdy, 2005). Known to date, the results of the study of representatives of the Bacilli class colonizing the human GIT mostly refer to ascertaining their positive, less often negative, impact on the body. We tried to systematize the available knowledge about compounds and complexes produced by these bacteria which serve as effectors triggering certain processes in the body (Figure 1), and identify the stage responsible for actually registered "influence." Bacilli introduced into the GIT through the consumption of fermented food do integrate the resident microbiome (Derrien and van Hylckama Vlieg, 2015) and contribute to its regulatory and health promoting action producing a variety of substances ranging from low molecular weight regulatory agents to proteins and peptides with antimicrobial and antitumor effects. Metabolites secreted by bacteria form a coat around the cells which contributes to nutrient supply, communication, and protection from damage caused by direct interaction with other species or their metabolites. Due to diffusion, the concentration of extracellular metabolites decreases with distance. To ensure that secreted components will reach their targets bacteria utilize membranous vesicles for their transportation.

\section{TOP-APPRECIATED COMPONENTS OF Bacilli SECRETOME}

It is well-appreciated that complex of enzymes (proteases, amylases, cellulases, lipases) secreted by Bacilli aid in digestion of food components in GIT (Khochamit et al., 2015; Keller et al., 2017). Bile salt hydrolases of lactobacilli reduce blood cholesterol and diminish the risk for cardiovascular diseases (Patel et al., 2010; Kumar et al., 2012). Recently, an antagonistic role of L. johnsonii La1 extracellular bile salt hydrolase against intestinal protozoan parasite Giardia duodenalis was revealed (Travers et al., 2016). Other enzymes like $N$-acylated homoserine lactone (AHL)-lactonase help to modulate the microbiota content by decreasing the number of quorum-sensing pathogenic bacteria in the GIT through direct disruption of their signal molecules (Vinoj et al., 2014; Zhou et al., 2016). Moreover, many enzymes are involved in the formation of metabolites which possess their own biological activities. For instance, during fermentation of milk and other proteinaceous products lactobacilli are able to release biologically active peptides with angiotensin I-converting enzyme (ACE)-inhibitory activity. Among these antihypertensive 

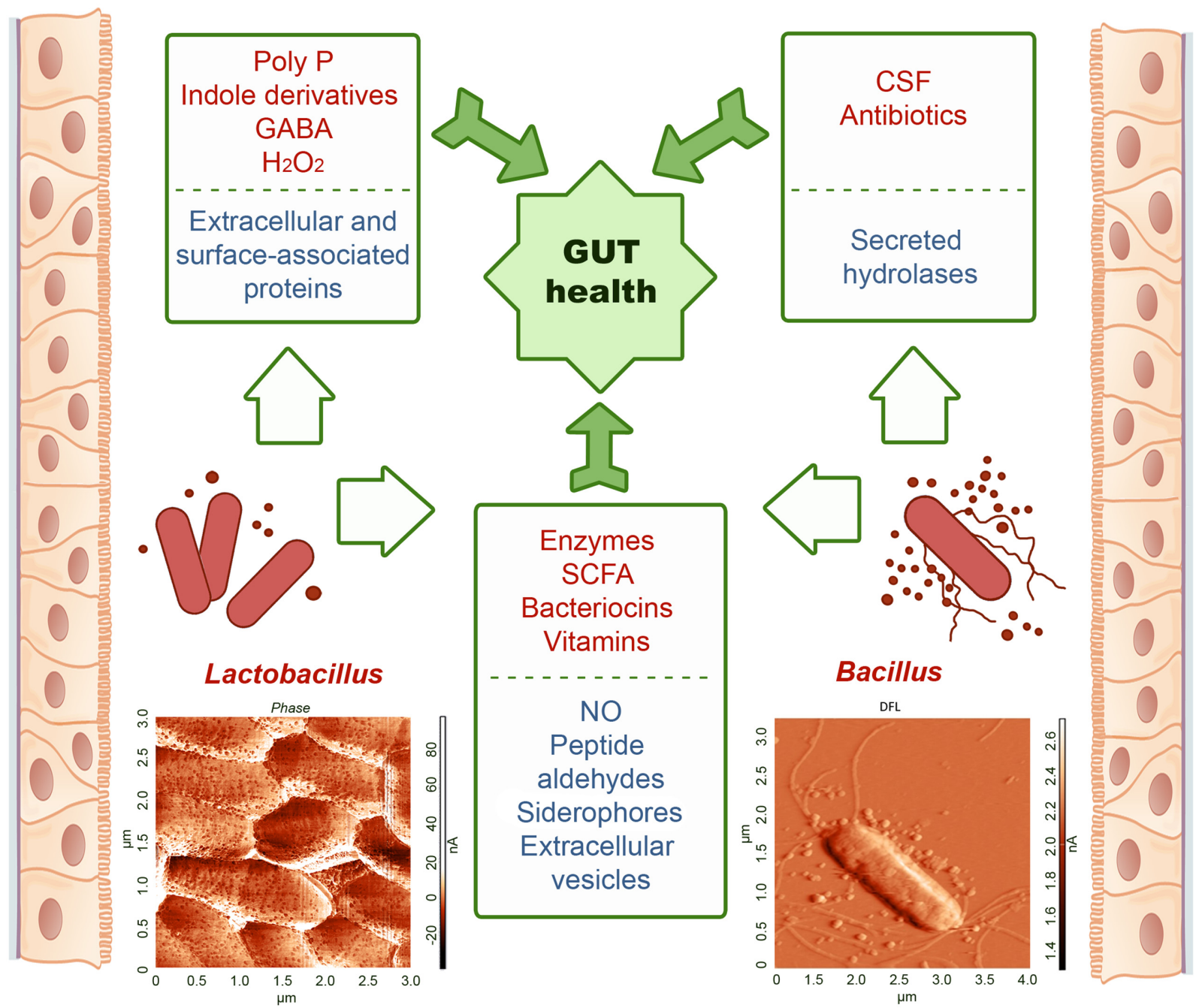

FIGURE 1 | Compounds secreted by the representatives of Lactobacillus and Bacillus mediating their beneficial effects in the GIT. Top-appreciated compounds are shown in upper part of panels, under-appreciated compounds - in lower parts. Both Lactobacillus and Bacillus are minor part of GIT microbiota. Of them, Lactobacillus spp. dominate quantitatively secreting a few compounds, while Bacillus spp. are less abundant but produce a variety of secreted substances with a wide spectrum of activities. Representatives of the Bacilli class were isolated from colon epithelia biopsy of the patients with diagnosed colorectal cancer. Atomic force microscopy images of $L$. plantarum (photo provided by Dr. Dina Yarullina) and B. pumilus (photo kindly provided by Dr. Galina Yakovleva) were obtained in air (contact mode) of stationary phase cells that were deposited on glass and dried prior analysis. Bacteria were identified using MALDI-TOF technique and 16S RNA sequencing. Representative AFM images show nanoscale structures on the cell surface and around the cells attributed to EVs.

peptides $\beta$-casein-derived tripeptides (lactotripeptides) are most studied (Hayes et al., 2007; Fekete et al., 2015).

Short-chain fatty acids are formed upon dietary carbohydrates fermentation by both Bacilli genera, studied in this review. The most common SCFA is lactate followed by acetic, propionic, butyric acids and minor isobutyrate, 2-methylpropionate, valerate, isovalerate, hexanoate. SCFAs are one of the most important gut microbial products affecting a range of host processes including energy utilization, hostmicrobe signaling, and control of colonic $\mathrm{pH}$. Decrease of a luminal $\mathrm{pH}$ creates an environment favoring beneficial species like Faecalibacterium prausnitzii and inappropriate for many others bacteria and yeasts (Nyangale et al., 2015). SCFAs positively influence the gut motility (Yang and Chiu, 2017) and intestinal secretion (Bhattarai et al., 2017), inhibit proliferation of tumor cells by apoptosis induction, stimulate production of insulin-like growth factor 1 promoting bone growth and remodeling (Yan et al., 2016), cause epigenetic modifications, regulate blood pressure and inflammation (Natarajan and Pluznick, 2014). The multifaceted roles of SCFAs nominate them for the key molecular link between diet, the microbiome and health.

Lactate produced by Lactobacillus provides an unfavorable environment for the growth of many pathogenic bacteria, it also acts as a permeabilizer of the Gram-negative bacterial outer membrane, thus increasing the susceptibility of pathogens 
to antimicrobial molecules, e.g., bacteriocins or host lysozyme (Alakomi et al., 2000). Strains of B. licheniformis and B. coagulans also ferment different sugars with formation of lactic acid (Wang et al., 2011; Nyangale et al., 2015). Butyrate is the local energy source for colonocytes (LeBlanc et al., 2017); also it plays an important role in maintenance of the gut barrier function through stimulation of tight junction integrity and mucin production (Peng et al., 2009; Jung et al., 2015). The SCFAs produced by the human gut microbiota are transported from the gut lumen with the bloodstream to a variety of different organs, where they are used in lipid and energy metabolism, particularly by the hepatocyte cells of the liver, which use propionate for gluconeogenesis, whilst acetate and butyrate are mostly involved in lipid biosynthesis (den Besten et al., 2013a). Besides, SCFAs appear to exert regulatory effects on gluconeogenesis and lipogenesis mediated by peroxisome proliferator-activated receptor gamma (PPAR $\gamma$ ) (den Besten et al., 2015) and protein kinases, such as AMP-activated protein kinase (Peng et al., 2009; den Besten et al., 2015) or mitogen-activated protein kinases (MAPK) (Jung et al., 2015). SCFAs have been reported to represent the natural ligands for free fatty acid receptors 2 and 3 (FFAR 2/3) (former G protein-coupled receptors, GPR43 and GPR41), involved in the regulation of lipid and glucose metabolism and found on a wide range of cell types, including enteroendocrine and immune cells (den Besten et al., 2013b). Moreover, as far as these receptors are expressed on neurons of the peripheral, autonomic and somatic nervous systems, SCFAs can modulate neuronal activity and visceral reflexes (Nøhr et al., 2015). SCFAs are considered as promising for the prevention and treatment of the metabolic syndrome, certain types of cancer, bowel disorders, such as ulcerative colitis, Crohn's disease, and antibiotic-associated diarrhea (den Besten et al., 2013b; RíosCovián et al., 2016).

Hydrogen peroxide $\left(\mathrm{H}_{2} \mathrm{O}_{2}\right)$ production by lactobacilli has been suggested to be a non-specific antimicrobial defense mechanism. L. jensenii, L. crispatus, L. gasseri, and L. acidophilus are the most common $\mathrm{H}_{2} \mathrm{O}_{2}$-producing lactobacilli inhabiting the human intestine and are often applied as probiotic supplements in the food industry (Martín and Suárez, 2010; Hertzberger et al., 2014). In gastrointestinal environment, SCFAs and bacteriocins have been considered as key antimicrobial factors, whereas the impact of $\mathrm{H}_{2} \mathrm{O}_{2}$ production remains underappreciated. However, $\mathrm{H}_{2} \mathrm{O}_{2}$, like other reactive oxygen species, exerts strong cytotoxicity against microorganisms. Although $\mathrm{H}_{2} \mathrm{O}_{2}$ itself is not highly reactive, it can readily diffuse across cellular membrane and through the Fenton reaction form highly reactive hydroxyl radicals, which cause oxidative damage to major biological macromolecules, e.g., oxidation of protein thiols, peroxidation of lipids, DNA base damage, and strand breakage of nucleic acids (Imlay, 2003; Valko et al., 2005). The role for $\mathrm{H}_{2} \mathrm{O}_{2}$ in the antiSalmonella activity of $L$. johnsonii NCC533, the human intestinal isolate and a probiotic strain, was revealed in vitro (Pridmore et al., 2008). L. delbrueckii VI1007 produces at least three growthinhibiting factors, other than lactic acid, one of which has been identified as $\mathrm{H}_{2} \mathrm{O}_{2}$ (Van De Guchte et al., 2001). $\mathrm{H}_{2} \mathrm{O}_{2}$ may contribute to the maintenance of the normal microbiota. Especially for the vaginal microbiota, strong evidence exists that colonization with $\mathrm{H}_{2} \mathrm{O}_{2}$-producing lactobacilli is associated with lower rates of bacterial vaginosis and HIV acquisition (Wilks et al., 2004; Balkus et al., 2012). Moreover, $\mathrm{H}_{2} \mathrm{O}_{2}$ may exert immunomodulatory properties. It was showed that $\mathrm{H}_{2} \mathrm{O}_{2}$, produced by $L$. crispatus M247, acts as a signal transducing molecule activating peroxisome proliferator activated receptor $\gamma$ $($ PPAR- $\gamma)$, which plays a central role in regulation of intestinal inflammation and homeostasis (Voltan et al., 2008). L. johnsoniiderived $\mathrm{H}_{2} \mathrm{O}_{2}$ has been shown to affect the activity of indoleamine 2,3-dioxygenase, an important immune modulator, both in vitro and in the rat model of type 1 diabetes (Valladares et al., 2013).

Poly P, a linear polymer of over 700 phosphate residues, is synthesized by Lactobacillus with the help of polyphosphate kinase (Alcántara et al., 2014). It suppresses the oxidantinduced intestinal permeability inducing cytoprotective heat shock proteins in mouse small intestine through activation of integrin $\beta 1$-p38 MAPK pathway (Segawa et al., 2011). Poly P was shown to improve the inflammation grade and survival rate in mice model of colitis (Segawa et al., 2011) and to inhibit viability of colon cancer cells via apoptosis through activation of the ERK pathway (Sakatani et al., 2016).

Indole derivatives formed from tryptophan by Lactobacillus cells act on the aryl hydrocarbon receptor in intestinal immune cells increasing IL-22 production which, in turns, beneficially impacts the immune system, enhances antifungal resistance and protection of mucosa from damage (Zelante et al., 2013; Lamas et al., 2016; Etienne-Mesmin et al., 2017). The main inhibitory neurotransmitter in the brain, GABA, is produced with the help of glutamate decarboxylase expressed by multiple strains of Lactobacillus (Barrett et al., 2012; Yunes et al., 2016).

Bacilli synthesize B-group vitamins including folate and biotin during the fermentation of foods in GIT and can exchange them, thereby enabling the survival of organisms that do not synthesize those (Magnúsdóttir et al., 2015).

A number of peptide and lipopeptide antibiotics and bacteriocins are produced by Bacilli both involving ribosomes and non-ribosomally (Zacharofa and Lovitt, 2012; Sumi et al., 2015; Zhao and Kuipers, 2016). These structurally diverse compounds suppress the growth of competing species and pathogens through different mechanisms primarily connected to membrane permeabilization (Fiedler and Heerklotz, 2015; Shobharani et al., 2015). Antimicrobial peptides of Bacilli were shown to be active against pathogenic bacteria such as Staphylococcus aureus, methicillin resistant $S$. aureus, Clostridium perfringens, Klebsiella sp., and common food spoilage bacteria such as B. cereus, Escherichia coli, Listeria monocytogenes, Pseudomonas aeruginosa, Aeromonas sp., Serratia marcescens, Pasteurella haemolytica, Salmonella enteritidis, and S. gallinarum (Ahmadova et al., 2013; Martinez et al., 2013; Berić et al., 2014; Ayed et al., 2015; Khochamit et al., 2015; Shobharani et al., 2015; Collins et al., 2016; Lim et al., 2016; Chauhan et al., 2017; Perez et al., 2017). Bacteriocins attract great interest with regard to their potential use as food preservatives (De Vuyst and Leroy, 2007; Kaškonienè et al., 2017) and are regarded as a promising alternative to prevent gastrointestinal infections (Dobson et al., 2012). 
Lactobacillus produces a number of bacteriocins usually active against closely related Gram-positive bacteria which are likely to reside in the same ecological niche. Most Lactobacillus bacteriocins are small, heat-stable cationic peptides which form pores in the cytoplasmic membrane of sensitive bacteria and thus cause leaking of target cells (Oscariz and Pisabarro, 2001). Other bacteriocins interrupt production of peptidoglycan or act by interfering with essential enzyme activities in susceptible bacteria (Servin, 2004). Bacteriocins from Lactobacillus are generally recognized as being inactive against Gram-negative organisms. However, it has been reported that bacteriocin from L. plantarum TN635 is active against Salmonella enterica ATCC43972, Pseudomonas aeruginosa ATCC 49189, Hafnia sp. and Serratia sp. (Smaoui et al., 2010). Moreover, a small bacteriocin $(<6.5 \mathrm{kDa})$ produced by $L$. acidophilus IBB 801 and designated as acidophilin 801, displayed bactericidal activity against E. coli Row and Salmonella panama 1467 (Zamfir et al., 1999). Bacteriocin OR-7 produced by L. salivarius NRRL B30514 resulted in reduction of Campylobacter jejuni colonization in chicken GI tracts when was added into feed. Interestingly, OR-7 had high sequence similarity to acidocin A, which was previously identified from L. acidophilus and had activity only to Gram-positive bacteria (Stern et al., 2006).

Bacillus is considered to be the second most important bacteriocin producer following lactic acid bacteria which differs from the latter by broad antimicrobial spectrum (Abriouel et al., 2011; Ayed et al., 2015). Bacteriocins and bacteriocin-like inhibitory substances produced by Bacillus exhibit antibacterial activity toward Gram-positive and Gram-negative bacteria as well as fungi, however, activity against Gram-positives is comparatively higher (Hyronimus et al., 1998; Rey et al., 2004; Arias et al., 2013; Berić et al., 2014; Chopra et al., 2014; Barbosa et al., 2015; Shobharani et al., 2015; Lee et al., 2016; Lim et al., 2016; Liu et al., 2017; Perez et al., 2017). Species of Bacillus differ by their antimicrobial potential (Perez et al., 2017). Non-ribosomal peptide antibiotics produced by Bacillus (bacitracin, proticin, lichenicidin, bacillaene) are essential for the protection of these bacteria from predation and antibiotics produced by other species (Rey et al., 2004; Barger et al., 2012; Alvarez-Ordóñez et al., 2014; Müller et al., 2014). Bacillus spp. were shown to produce a mixture of different lipopeptides with antimicrobial activities (Huang et al., 2006). B. subtilis produces surfactins, fengycins and iturins in a ratio of 6:37:57 (Fiedler and Heerklotz, 2015; Perez et al., 2017). The less abundant surfactins unlike other types of Bacillus lipopeptides exhibit a broad range of antimicrobial activities and possess antiviral action (Huang et al., 2006). They protect bacilli against extracellular antibiotic-containing vesicles of other species (Brown et al., 2014) and inhibit phospholipase A2 resulting in subsequent downregulation of pro-inflammatory cytokines and upregulation of anti-inflammatory cytokines (Selvam et al., 2009).

Probiotic effect of B. subtilis was shown to be connected to competence and sporulation factor, a small quorum-sensing peptide involved in bacteria communication, proliferation and sporulation (Okamoto et al., 2012). CSF activates the Akt and p38 MAPK pathways and exerts its anti-inflammatory effect by downregulation of pro-inflammatory mediators (IL-4, IL6, and CXCL-1), the upregulation of anti-inflammatory IL-10, and the induction of cytoprotective heat shock protein Hsp27 in the intestinal epithelia (Okamoto et al., 2012). The similar effects were observed for two peptides secreted by B. megaterium isolated from human ileal biopsies of healthy volunteers (Di Luccia et al., 2016). Effects of CSF depend on its uptake by an organic cation transporter-2 in intestine which helps the host to monitor and respond to changes in the behavior or composition of colonic microbiota (Fujiya et al., 2007).

\section{UNDER-APPRECIATED COMPONENTS OF Bacilli SECRETOME}

Extracellular and surface-associated proteins secreted by commensal bacteria play an important role in gut colonization and persistence. Moreover, some of them can interact directly with mucosal cells, activating signaling pathways that lead to different cytokine secretion and gene expression profiles (Tsilingiri and Rescigno, 2013). For instance, two secreted proteins p75 and p40 (also known as Msp1 and Msp2) of L. rhamnosus GG have been demonstrated to prevent cytokineinduced cell apoptosis by activating the antiapoptotic protein kinase $\mathrm{B}$ and by inhibiting the pro-apoptotic MAPK (Yan and Polk, 2002; Yan et al., 2007), reduce TNF induced epithelial damage in the colon and as a result promote epithelial homeostasis (Yan et al., 2007). Homologs of genes that encode for $\mathrm{p} 40$ and $\mathrm{p} 75$ were also found in the genomes of $L$. casei and $L$. rhamnosus; the proteins from L. casei BL23 were demonstrated to elicit similar host responses (Bäuerl et al., 2010).

Secreted hydrolytic enzymes contribute to probiotic effects of Bacilli due to their ability to decompose food polymers releasing digestive discomfort. However, accumulating data indicate that these proteins might be involved in a complex interaction with host and its microbiota. Hydrolases demonstrate direct antimicrobial activity. Proteases, glycoside hydrolases and DNases participate in dispersal of bacterial biofilms and inhibition of biofilm formation (Chen et al., 2013; Nguyen and Burrows, 2014; Watters et al., 2016; Fleming and Rumbaugh, 2017). Extracellular nuclease, NucB, from B. licheniformis, was shown to digest extracellular DNA in biofilms of staphylococci and streptococci associated with chronic rhinosinusitis proving enzyme effectiveness in eradicating biofilms of multidrugresistant bacteria (Shields et al., 2013). Secretion of lowmolecular-weight guanyl-preferring ribonucleases (RNases) is a distinct feature of some Bacillus species (Ulyanova et al., 2016). A well-studied representative of these RNases, binase from B. pumilus, has manifested antitumor (Ulyanova et al., 2011; Cabrera-Fuentes et al., 2013; Mitkevich et al., 2013) and antiviral activities (Shah Mahmud and Ilinskaya, 2013; Ilinskaya and Shah Mahmud, 2014; Shah Mahmud et al., 2016, 2017; Müller et al., 2017). KRAS which has mutations in about $40 \%$ of patients with colorectal cancer (Prior et al., 2012) was shown to be a direct target for antitumor binase (Ilinskaya et al., 2016). $2^{\prime}, 3^{\prime}$-cGMP generated by binase upon RNA cleavage (Sokurenko et al., 2015) 
may also contribute to modulation of host cells physiology, since it is able to duplicate its counterpart $3^{\prime}, 5^{\prime}$-cGMP (Boadu et al., 2001) and can exhibit its own regulatory functions. Extracellular cGMP enhances extracellular adenosine and reduces uric acid levels which may render tissue protective effect upon injury (Jackson et al., 2013). Guanylate cyclase which catalyzes the synthesis of cGMP from GTP is represented in the cell membranes along the intestine. The cGMP signaling regulates intestinal fluid and electrolyte balance, epithelial homeostasis, mucosal barrier integrity, visceral sensation through ERK and AKT pathways (Han et al., 2011; Lin et al., 2012; Hannig et al., 2014; Lan et al., 2016). Increased cGMP levels in the colon epithelium activate antioxidant gene expression (Wang et al., 2017). cGMP expression is significantly decreased upon ulcerative colitis and colon cancer (Lin et al., 2012; Lan et al., 2016; Pattison et al., 2016). cGMP and ways for enhancement of its production are considered for treatment of irritable bowel syndrome by decreasing of gastrointestinal pain and abdominal sensory symptoms (Lan et al., 2016) and as a tool for tumor suppression (Pattison et al., 2016).

Recently, gut Firmicutes were shown to produce peptide aldehydes, cell-permeable protease inhibitors with a half-life of hours, which target cathepsins in the host lysosome blocking immune recognition of these mutualistic species and enabling them to reside in gut epithelial (Guo et al., 2017).

Nitric oxide is a well-known ubiquitous molecular mediator produced in mammals by the NOS isoforms at a catalytic site comprising a heme associated with a biopterin cofactor. Genome sequencing has shown the presence of genes encoding for proteins that are highly homologous to the oxygenase domain of mammalian NOS in bacteria, including those of the class Bacilli: S. aureus (Bird et al., 2002; Salard et al., 2006), B. subtilis (Adak et al., 2002), B. anthracis (Midha et al., 2005; Salard et al., 2006), Geobacillus stearothermophilus (Sudhamsu and Crane, 2006), L. fermentum (Morita et al., 1997), and L. plantarum (Adawi et al., 1997; Iarullina et al., 2006; Iarullina and Ilinskaia, 2007; Yarullina et al., 2015). So, intestinal Bacilli have NOS that is evolutionary related to the mammalian enzymes. Moreover, as bacteria have the most ancient version of NOS, it was hypothesized that Eukaryotes acquired NOS from bacteria by horizontal gene transfer (Gusarov et al., 2013). Recently, the conservation of NOS-derived NO-heme receptor signaling between bacteria and mammals was proved (Kinkel et al., 2016). NO as reactive oxygen molecule is widely considered as important participant in the immune system of different organisms to confront microbial infections. Thus, inhibition of bacterial NOS has the potential to improve the efficacy of antimicrobials used to treat infections by Gram-positive pathogens S. aureus and B. anthracis possessing this enzyme (Holden et al., 2015). Commensal microbiotaderived NO has been shown to influence host physiology. NO synthesized by L. plantarum takes part in the regulation of intestinal motility in rat (Yarullina et al., 2016). Being a signaling molecule, NO released by B. subtilis in the intestine of Caenorhabditis elegans initiates a signaling cascade that results in the induction of 65 genes, including hsps and several other genes that have been implicated in longevity and stress resistance (Gusarov et al., 2013). Involvement of bacterial NO in human cardiovascular system is under investigation (Cabrera-Fuentes et al., 2016).

Ferrichrome of $L$. casei was identified as a tumor-suppressive molecule on colon cancer cells which induces apoptosis via activation of c-jun N-terminal kinase (JNK) (Konishi et al., 2016). Many siderophore-binding proteins were found in EVs of B. subtilis (Dubois et al., 2009; Brown et al., 2014). Siderophores can endow bacilli advantage in competition for low-available iron with pathogenic bacteria. Iron cations are potent crosslinkers of the biofilm matrix (Chen and Stewart, 2002) and their chelation causes dispersal of biofilms (Sobke et al., 2012).

Over the last decade, extracellular vesicles have emerged as prominent vehicles of biological signals. Intense research on that topic revealed that EVs play important roles in bacterial physiology and pathogenesis, ranging from secretion and delivery of biomolecules (for example, toxins, DNA, or quorum sensing molecules) over stress response and biofilm formation to immunomodulation and adherence to host cells (Roier et al., 2016). Both Bacillus and Lactobacillus species were reported to produce EVs, spherical membranous structures of $20-150 \mathrm{~nm}$ in diameter (Brown et al., 2014, 2015; Avila-Calderón et al., 2015; Behzadi et al., 2017; Li et al., 2017). EVs are formed both in planktonic cultures and bacterial biofilms where they help to maintain biofilm cohesion. The quantity of EVs varies with the strain (Brown et al., 2014), conditions and stage of growth (Kim et al., 2016). Thus, EVs can be produced by Bacilli in GIT.

The EVs are enriched with proteins, lipids, nucleic acids, and metabolites which exhibit biological activities. Release of vesicular cargo is achieved by direct intercellular transfer mediated by the membranes fusion (Kim et al., 2016; Stubbendieck and Straight, 2016) or by production of special molecules like lipopeptide surfactin which disrupts EVs unspecifically (Brown et al., 2014). Therefore, proteins with specific biological activities can be directly delivered inside EVs into other cells ensuring their penetration. In Gram-positive bacteria, proteins secreted via specific pathways are believed to be important for nutrient acquisition, detoxification, competitive survival, and communication (Brown et al., 2015). Recent findings support the importance of EVs for interaction of bacteria with each other and the host cells (Kim et al., 2016).

Extracellular vesicles carry hydrolytic enzymes for nutrient acquisition from extracellular complex substrates or key nutrients to feed sibling cells and contain specific agents for antagonizing competing species. In EV important for survival compounds are protected from damage retaining activities much longer and can be transported in concentrated amounts for long distances from producing cells. Among these compounds are antibiotics and hydrolytic enzymes including peptidoglycandegrading hydrolases (Mashburn and Whiteley, 2005; Alves et al., 2016; Stubbendieck and Straight, 2016). EVs isolated from B. subtilis contain proteins which are mostly associated with metabolic pathways including biosynthesis of secondary metabolites (Brown et al., 2014; Kim et al., 2016). Proteins with oxidoreductase and nucleotide binding activities are abundant in vegetative EVs, while proteins with hydrolytic, nucleic acid binding, and structural activity are predominant in sporulating EV (Kim et al., 2016). In EVs of sporulating B. subtilis superoxide 
dismutase, alkaline phosphatase III, polyketide synthase PKsM (associated with antibiotic activity) were identified (Kim et al., 2016). Sunl protein which confers self-immunity to antibiotic sublancin and many siderophore-binding proteins were found in EVs of B. subtilis (Dubois et al., 2009; Brown et al., 2014). The targeted lysis of EVs by surfactin of B. subtilis is hypothesized to guard bacilli from alien EVs and disrupt cell signaling by means of EVs in competing populations (Stubbendieck and Straight, 2016). EVs were also shown to adsorb phages (Biller et al., 2014).

Interaction of EVs with the host is specific to the microorganism from which the EVs were produced and is based on the lipid content and cargo of the EVs (Brown et al., 2015). Gram-positive bacterial EVs are composed of various fatty acids which might have a positive effect on host organism (Rivera et al., 2010). EVs were shown to elicit protective immune response in host (Vargas et al., 2015). For example, treatment of C. elegans with EVs originated from L. plantarum WCFS1 led to increased transcription of host defense genes, cpr-1 and clec-60, and thus provided protection against vancomycinresistant Enterococcus faecium. Moreover, in human Caco-2 cells these EVs had similar effect, leading to the upregulation of REG3G, which is functionally similar to clec-60, and CTSB, the human ortholog of $c p r-1$ (Li et al., 2017). The EVs from $B$. lentus isolated from Korean soybean fermented food induced apoptosis of human colon carcinoma cells HCT116 (Yang et al., 2016). EVs derived from L. rhamnosus GG are likely to be implicated in the anti-cancer activity as they induce apoptosis in the hepatic adenocarcinoma cell line HepG2 via augmentation of the expression ratio between pro- and anti-apoptotic genes bax/bcl-2 (Behzadi et al., 2017).

\section{CONCLUSION AND FURTHER PERSPECTIVES}

Now, it has become clear that studies on phylotype profiling are limited to the identification of microbial constituents, where information is lacking about the molecular interaction of bacterial communities with the host. Lactobacilli are wellrepresented in the human GIT and secrete a number of compounds which have direct and indirect effects on the health of GIT and organism as a whole. Species of Bacillus genus are much less abundant but are capable of producing several times more extracellular molecules than lactobacilli. Many of

\section{REFERENCES}

Abriouel, H., Franz, C. M. A. P., Omar, N. B., and Galvez, A. (2011). Diversity and applications of Bacillus bacteriocins. FEMS Microbiol. Rev. 35, 201-232. doi: 10.1111/j.1574-6976.2010.00244.x

Adak, S., Aulak, K. S., and Stuehr, D. J. (2002). Direct evidence for nitric oxide production by a nitric-oxide synthase-like protein from Bacillus subtilis. J. Biol. Chem. 277, 16167-16171. doi: 10.1074/jbc.M201136200

Adawi, D., Kasravi, F. B., Molin, G., and Jeppsson, B. (1997). Effect of Lactobacillus supplementation with and without arginine on liver damage and bacterial translocation in an acute liver injury model in the rat. Hepatology 25, 642-647. doi: 10.1002/hep. 510250325 them still require exploration. Further deep studies are needed for better understanding of the complex interactions between human organism and its microbiota, clarification of the particular mechanisms underlying remarkable beneficial properties of probiotic Bacilli, and the specific action of innumerous secreted low- and high-molecular weight compounds and their vesicular transportation.

\section{AUTHOR CONTRIBUTIONS}

The basis of this review was the experimental work of the group led by ONI, in which a variety of biological activities of bacilli and lactobacilli secretome was established. ONI developed the main idea of this review, collected literature data, verified the text and coordinated it with co-authors carrying out the general guidance of the review. The part of the review devoted to the properties of representatives of the genus Bacillus and the components of their secretome belongs to VVU. She structured the review and created the scheme summarizing the main idea of the review on the diversity of components secreted by the representatives of Bacilli class. DRY, being a specialist in the field of probiotic activity of lactobacilli, analyzed data on the influence of Lactobacillus and their metabolites on intestinal functions and microbiota, and host organism. IGG collected literature data on the microflora of the human intestine. On the basis of his analysis of epithelial biopsy samples obtained during the operations of patients with diagnosed colorectal cancer, a conclusion about the contribution of Bacilli class to the microbiota closely associated with the epithelium was made.

\section{FUNDING}

The research was performed within the Russian Government Program of Competitive Growth of Kazan Federal University and supported by the Russian Science Foundation grant No 14-14-00522.

\section{ACKNOWLEDGMENTS}

Authors are thankful to Anna Makeeva for contribution to the Figure and to Galina Yakovleva for providing AFM image of B. pumilus.

Ahmadova, A., Todorov, S. D., Hadji-Sfaxi, I., Choiset, Y., Rabesona, H., Messaoudi, S., et al. (2013). Antimicrobial and antifungal activities of Lactobacillus curvatus strain isolated from homemade Azerbaijani cheese. Anaerobe 20, 42-49. doi: 10.1016/j.anaerobe.2013.01.003

Alakomi, H. L., Skytta, E., Saarela, M., Mattila-Sandholm, T., Latva-Kala, K., and Helander, I. M. (2000). Lactic acid permeabilizes gram-negative bacteria by disrupting the outer membrane. Appl. Environ. Microbiol. 66, 2001-2005. doi: 10.1128/AEM.66.5.2001-2005.2000

Alcántara, C., Blasco, A., Zúñiga, M., and Monedero, V. (2014). Accumulation of polyphosphate in Lactobacillus spp. and its involvement in stress resistance. Appl. Environ. Microbiol. 80, 1650-1659. doi: 10.1128/AEM. 03997-13 
Almand, E. A., Moore, M. D., Outlaw, J., and Jaykus, L. A. (2017). Human norovirus binding to select bacteria representative of the human gut microbiota. PLoS ONE 12:e0173124. doi: 10.1371/journal.pone.0173124

Alou, M. T., Fournier, P. E., and Raoult, D. (2016). “Bacillus mediterraneensis," a new bacterial species isolated from human gut microbiota. New Microbes New Infect. 12, 86-87. doi: 10.1016/j.nmni.2016.05.006

Alvarez-Ordóñez, A., Begley, M., Clifford, T., Deasy, T., Considine, K., O'Connor, P., et al. (2014). Investigation of the antimicrobial activity of Bacillus licheniformis strains isolated from retail powdered infant milk formulae. Probiotics Antimicrob. Proteins 6, 32-40. doi: 10.1007/s12602-013-9151-1

Alves, N. J., Turner, K. B., Medintz, I. L., and Walper, S. A. (2016). Protecting enzymatic function through directed packaging into bacterial outer membrane vesicles. Sci. Rep. 6:24866. doi: 10.1038/srep24866

Arias, A. A., Ongena, M., Devreese, B., Terrak, M., Joris, B., and Fickers, P. (2013). Characterization of amylolysin, a novel lantibiotic from Bacillus amyloliquefaciens GA1. PLoS ONE 8:e83037. doi: 10.1371/journal.pone. 0083037

Avila-Calderón, E. D., Araiza-Villanueva, M. G., Cancino-Diaz, J. C., LópezVillegas, E. O., Sriranganathan, N., Boyle, S. M., et al. (2015). Roles of bacterial membrane vesicles. Arch. Microbiol. 197, 1-10. doi: 10.1007/s00203-0141042-7

Ayed, H. B., Maalej, H., Hmidet, N., and Nasri, M. (2015). Isolation and biochemical characterisation of a bacteriocin-like substance produced by Bacillus amyloliquefaciens An6. J. Glob. Antimicrob. Resist. 3, 255-261. doi: 10.1016/j.jgar.2015.07.001

Balkus, J. E., Mitchell, C., Agnew, K., Liu, C., Fiedler, T., Cohn, S. E., et al. (2012). Detection of hydrogen peroxide-producing Lactobacillus species in the vagina: a comparison of culture and quantitative PCR among HIV-1 seropositive women. BMC Infect. Dis. 12:188. doi: 10.1186/1471-2334-12-188

Barbosa, J., Caetano, T., and Mendo, S. (2015). Class I and class II lanthipeptides produced by Bacillus spp. J. Nat. Prod. 78, 2850-2866. doi: 10.1021/np $500424 y$

Barger, S. R., Hoefler, B. C., Cubillos-Ruiz, A., Russell, W. K., Russell, D. H., and Straight, P. D. (2012). Imaging secondary metabolism of Streptomyces sp. Mg1 during cellular lysis and colony degradation of competing Bacillus subtilis. Antonie Van Leeuwenhoek 102, 435-445. doi: 10.1007/s10482-012-9769-0

Barrett, E., Ross, R. P., O’Toole, P. W., Fitzgerald, G. F., and Stanton, C. (2012). $\gamma$-Aminobutyric acid production by culturable bacteria from the human intestine. J. Appl. Microbiol. 113, 411-417. doi: 10.1111/j.1365-2672.2012. 05344.x

Bäuerl, C., Perez-Martinez, G., Yan, F., Polk, D. B., and Monedero, V. (2010). Functional analysis of the $\mathrm{p} 40$ and 75 proteins from Lactobacillus casei BL23. J. Mol. Microbiol. Biotechnol. 19, 231-241. doi: 10.1159/000322233

Behzadi, E., Hosseini, H. M., and Imani Fooladi, A. A. (2017). The inhibitory impacts of Lactobacillus rhamnosus GG-derived extracellular vesicles on the growth of hepatic cancer cells. Microb. Pathog. doi: 10.1016/j.micpath.2017.06. 016 [Epub ahead of print].

Bene, K., Varga, Z., Petrov, V. O., Boyko, N., and Rajnavolgyi, E. (2017). Gut microbiota species can provoke both inflammatory and tolerogenic immune responses in human dendritic cells mediated by retinoic acid receptor alpha ligation. Front. Immunol. 8:427. doi: 10.3389/fimmu.2017.00427

Bérdy, J. (2005). Bioactive microbial metabolites. J. Antibiot. 58, 1-26. doi: 10.1038/ ja.2005.1

Berić, T., Stanković, S., Draganić, V., Kojić, M., Lozo, J., and Fira, D. (2014). Novel antilisterial bacteriocin licheniocin 50.2 from Bacillus licheniformis VPS50.2 isolated from soil sample. J. Appl. Microbiol. 116, 502-510. doi: $10.1111 /$ jam. 12393

Bermudez-Brito, M., Plaza-Díaz, J., Muñoz-Quezada, S., Gómez-Llorente, C., and Gil, A. (2012). Probiotic mechanisms of action. Ann. Nutr. Metab. 61, 160-174. doi: 10.1159/000342079

Bhattarai, Y., Schmidt, B. A., Linden, D. R., Larson, E. D., Grover, M., Beyder, A., et al. (2017). Human derived gut microbiota modulates colonic secretion in mice by regulating 5-HT3 receptor expression via acetate production. Am. J. Physiol. Gastrointest. Liver Physiol. 313, G80-G87. doi: 10.1152/ajpgi.00448. 2016

Biller, S. J., Schubotz, F., Roggensack, S. E., Thompson, A. W., Summons, R. E., and Chisholm, S. W. (2014). Bacterial vesicles in marine ecosystems. Science 343, 183-186. doi: 10.1126/science. 1243457
Bird, L. E., Ren, J., Zhang, J., Foxwell, N., Hawkins, A. R., Charles, I. G., et al. (2002). Crystal structure of SANOS, a bacterial nitric oxide synthase oxygenase protein from Staphylococcus aureus. Structure 10, 1687-1696. doi: 10.1016/ S0969-2126(02)00911-5

Boadu, E., Vaskinn, S., Sundkvist, E., Jaeger, R., and Sager, G. (2001). Inhibition by guanosine cyclic monophosphate (cGMP) analogues of uptake of [(3)H]3, 5'cGMP without stimulation of ATPase activity in human erythrocyte insideout vesicles. Biochem. Pharmacol. 62, 425-429. doi: 10.1016/S0006-2952(01) 00682-7

Brown, L., Kessler, A., Cabezas-Sanchez, P., Luque-Garcia, J. L., and Casadevall, A. (2014). Extracellular vesicles produced by the Gram-positive bacterium Bacillus subtilis are disrupted by the lipopeptide surfactin. Mol. Microbiol. 93, 183-198. doi: $10.1111 / \mathrm{mmi} .12650$

Brown, L., Wolf, J. M., Prados-Rosales, R., and Casadevall, A. (2015). Through the wall: extracellular vesicles in Gram-positive bacteria, mycobacteria and fungi. Nat. Rev. Microbiol. 13, 620-630. doi: 10.1038/nrmicro3480

Browne, H. P., Forster, S. C., Anonye, B. O., Kumar, N., Neville, B. A., Stares, M. D., et al. (2016). Culturing of 'unculturable' human microbiota reveals novel taxa and extensive sporulation. Nature 533, 543-546. doi: 10.1038/nature17645

Cabrera-Fuentes, H. A., Alba-Alba, C., Aragones, J., Bernhagen, J., Boisvert, W. A., Bøtker, H. E., et al. (2016). Meeting report from the 2 nd International Symposium on New Frontiers in Cardiovascular Research. Protecting the cardiovascular system from ischemia: between bench and bedside. Basic Res. Cardiol. 111, 7. doi: 10.1007/s00395-015-0527-0

Cabrera-Fuentes, H. A., Aslam, M., Saffarzadeh, M., Kolpakov, A., Zelenikhin, P., Preissner, K. T., et al. (2013). Internalization of Bacillus intermedius ribonuclease (BINASE) induces human alveolar adenocarcinoma cell death. Toxicon 69, 219-226. doi: 10.1016/j.toxicon.2013.03.015

Camilleri, M. (2006). Probiotics and irritable bowel syndrome: rationale, putative mechanisms, and evidence of clinical efficacy. J. Clin. Gastroenterol. 40, 264269. doi: 10.1097/00004836-200603000-00020

Carding, S., Verbeke, K., Vipond, D. T., Corfe, B. M., and Owen, L. J. (2015). Dysbiosis of the gut microbiota in disease. Microb. Ecol. Health Dis. 26:26191. doi: 10.3402/mehd.v26.26191

Chauhan, A. K., Maheshwari, D. K., and Bajpai, V. K. (2017). Isolation and preliminary characterization of a bacteriocin-producer Bacillus strain inhibiting methicillin resistant Staphylococcus aureus. Acta Biol. Hung. 68, 208-219. doi: 10.1556/018.68.2017.2.8

Chen, C., Krishnan, V., Macon, K., Manne, K., Narayana, S. V. L., and Schneewind, O. (2013). Secreted proteases control autolysin-mediated biofilm growth of Staphylococcus aureus. J. Biol. Chem. 288, 29440-29452. doi: 10.1074/ jbc.M113.502039

Chen, X., and Stewart, P. S. (2002). Role of electrostatic interactions in cohesion of bacterial biofilms. Appl. Microbiol. Biotechnol. 59, 718-720. doi: 10.1007/ s00253-002-1044-2

Choi, C. H., Kwon, J. G., Kim, S. K., Myung, S. J., Park, K. S., Sohn, C. I., et al. (2015). Efficacy of combination therapy with probiotics and mosapride in patients with IBS without diarrhea: a randomized, double-blind, placebocontrolled, multicenter, Phase II trial. Neurogastroenterol. Motil. 27, 705-716. doi: $10.1111 /$ nmo. 12544

Chopra, L., Singh, G., Choudhary, V., and Sahoo, D. K. (2014). Sonorensin: an antimicrobial peptide, belonging to the heterocycloanthracin subfamily of bacteriocins, from a new marine isolate, Bacillus sonorensis MT93. Appl. Environ. Microbiol. 80, 2981-2990. doi: 10.1128/AEM.04259-13

Clemente, J. C., Ursell, L. K., Parfrey, L. W., and Knight, R. (2012). The impact of the gut microbiota on human health: an integrative view. Cell 148, 1258-1270. doi: 10.1016/j.cell.2012.01.035

Collins, F. W., O'Connor, P. M., O’Sullivan, O., Rea, M. C., Hill, C., and Ross, R. P. (2016). Formicin - a novel broad-spectrum two-component lantibiotic produced by Bacillus paralicheniformis APC 1576. Microbiology 162, 1662-1671. doi: 10.1099/mic.0.000340

De Vuyst, L., and Leroy, F. (2007). Bacteriocins from lactic acid bacteria: production, purification, and food applications. J. Mol. Microbiol. Biotechnol. 13, 194-199. doi: 10.1159/000104752

den Besten, G., Bleeker, A., Gerding, A., van Eunen, K., Havinga, R., van Dijk, T. H., et al. (2015). Short-chain fatty acids protect against high-fat diet-induced obesity via a PPAR $\gamma$-dependent switch from lipogenesis to fat oxidation. Diabetes Metab. Res. Rev. 64, 2398-2408. doi: 10.2337/db14-1213 
den Besten, G., Lange, K., Havinga, R., van Dijk, T. H., Gerding, A., van Eunen, K., et al. (2013a). Gut-derived short-chain fatty acids are vividly assimilated into host carbohydrates and lipids. Am. J. Physiol. Gastrointest. Liver Physiol. 305, G900-G910. doi: 10.1152/ajpgi.00265.2013

den Besten, G., van Eunen, K., Groen, A. K., Venema, K., Reijngoud, D. J., and Bakker, B. M. (2013b). The role of short-chain fatty acids in the interplay between diet, gut microbiota, and host energy metabolism. J. Lipid Res. 54, 2325-2340. doi: 10.1194/jlr.R036012

Derrien, M., and van Hylckama Vlieg, J. E. (2015). Fate, activity, and impact of ingested bacteria within the human gut microbiota. Trends Microbiol. 23, 354-366. doi: 10.1016/j.tim.2015.03.002

Dethlefsen, L., Huse, S., Sogin, M. L., and Relman, D. A. (2008). The pervasive effects of an antibiotic on the human gut microbiota, as revealed by deep 16S rRNA sequencing. PLoS Biol. 6:e280. doi: 10.1371/journal.pbio. 0060280

Di Luccia, B., D’Apuzzo, E., Varriale, F., Baccigalupi, L., Ricca, E., and Pollice, A. (2016). Bacillus megaterium SF185 induces stress pathways and affects the cell cycle distribution of human intestinal epithelial cells. Benef. Microbes 7, 609-620. doi: 10.3920/BM2016.0020

Dobson, A., Cotter, P. D., Ross, R. P., and Hill, C. (2012). Bacteriocin production: a probiotic trait? Appl. Environ. Microbiol. 78, 1-6. doi: 10.1128/AEM.05576-11

Donaldson, G. P., Lee, S. M., and Mazmanian, S. K. (2016). Gut biogeography of the bacterial microbiota. Nat. Rev. Microbiol. 14, 20-32. doi: 10.1038/ nrmicro3552

Donia, M. S., Cimermancic, P., Schulze, C. J., Wieland Brown, L. C., Martin, J., Mitreva, M., et al. (2014). A systematic analysis of biosynthetic gene clusters in the human microbiome reveals a common family of antibiotics. Cell 158, 1402-1414. doi: 10.1016/j.cell.2014.08.032

Dubois, J. Y., Kouwen, T. R., Schurich, A. K., Reis, C. R., Ensing, H. T., Trip, E. N., et al. (2009). Immunity to the bacteriocin sublancin 168 is determined by the SunI (YolF) protein of Bacillus subtilis. Antimicrob. Agents Chemother. 53, 651-661. doi: 10.1128/AAC.01189-08

Ebel, B., Lemetais, G., Beney, L., Cachon, R., Sokol, H., Langella, P., et al. (2014). Impact of probiotics on risk factors for cardiovascular diseases. A review. Crit. Rev. Food Sci. Nutr. 54, 175-189. doi: 10.1080/10408398.2011.579361

Etienne-Mesmin, L., Chassaing, B., and Gewirtz, A. T. (2017). Tryptophan: a gut microbiota-derived metabolites regulating inflammation. World J. Gastrointest. Pharmacol. Ther. 8, 7-9. doi: 10.4292/wjgpt.v8.i1.7

Fakhry, S., Sorrentini, I., Ricca, E., De Felice, M., and Baccigalupi, L. (2008). Characterization of spore forming Bacilli isolated from the human gastrointestinal tract. J. Appl. Microbiol. 105, 2178-2186. doi: 10.1111/j.13652672.2008.03934.x

Fekete, Á. A., Givens, D. I., and Lovegrove, J. A. (2015). Casein-derived lactotripeptides reduce systolic and diastolic blood pressure in a meta-analysis of randomised clinical trials. Nutrients 7, 659-681. doi: 10.3390/nu7010659

Fiedler, S., and Heerklotz, H. (2015). Vesicle leakage reflects the target selectivity of antimicrobial lipopeptides from Bacillus subtilis. Biophys. J. 109, 2079-2089. doi: 10.1016/j.bpj.2015.09.021

Fleming, D., and Rumbaugh, K. P. (2017). Approaches to dispersing medical biofilms. Microorganisms 5:E15. doi: 10.3390/microorganisms5020015

Fransen, F., Zagato, E., Mazzini, E., Fosso, B., Manzari, C., El Aidy, S., et al. (2015). $\mathrm{BALB} / \mathrm{c}$ and $\mathrm{C} 57 \mathrm{BL} / 6$ mice differ in polyreactive IgA abundance, which impacts the generation of antigen-specific IgA and microbiota diversity. Immunity 43, 527-540. doi: 10.1016/j.immuni.2015.08.011

Fujiya, M., Musch, M. W., Nakagawa, Y., Hu, S., Alverdy, J., Kohgo, Y., et al. (2007). The Bacillus subtilis quorum-sensing molecule CSF contributes to intestinal homeostasis via OCTN2, a host cell membrane transporter. Cell Host Microbe 1, 299-308. doi: 10.1016/j.chom.2007.05.004

Gagnière, J., Raisch, J., Veziant, J., Barnich, N., Bonnet, R., Buc, E., et al. (2016). Gut microbiota imbalance and colorectal cancer. World J. Gastroenterol. 22, 501-518. doi: 10.3748/wjg.v22.i2.501

Gao, Z., Guo, B., Gao, R., Zhu, Q., and Qin, H. (2015). Microbiota disbiosis is associated with colorectal cancer. Front. Microbiol. 6:20. doi: 10.3389/fmicb. 2015.00020

Ghelardi, E., Celandroni, F., Salvetti, S., Gueye, S. A., Lupetti, A., and Senesi, S. (2015). Survival and persistence of Bacillus clausii in the human gastrointestinal tract following oral administration as spore-based probiotic formulation. J. Appl. Microbiol. 119, 552-559. doi: 10.1111/jam.12848
Ghoshal, U. C., Shukla, R., and Ghoshal, U. (2017). Small intestinal bacterial overgrowth and irritable bowel syndrome: a bridge between functional organic dichotomy. Gut Liver 11, 196-208. doi: 10.5009/gnl16126

Ghouri, Y. A., Richards, D. M., Rahimi, E. F., Krill, J. T., Jelinek, K. A., Dupont, A. W., et al. (2014). Systematic review of randomized controlled trials of probiotics, prebiotics, and synbiotics in inflammatory bowel disease. Clin. Exp. Gastroenterol. 7, 473-487. doi: 10.2147/CEG.S27530

Giraffa, G., Chanishvili, N., and Widyastuti, Y. (2010). Importance of lactobacilli in food and feed biotechnology. Res. Microbiol. 161, 480-487. doi: 10.1016/j. resmic.2010.03.001

Guo, C. J., Chang, F. Y., Wyche, T. P., Backus, K. M., Acker, T. M., Funabashi, M., et al. (2017). Discovery of reactive microbiota-derived metabolites that inhibit host proteases. Cell 168, 517.e18-526.e18. doi: 10.1016/j.cell.2016.12.021

Gusarov, I., Gautier, L., Smolentseva, O., Shamovsky, I., Eremina, S., Mironov, A., et al. (2013). Bacterial nitric oxide extends the lifespan of C. elegans. Cell 152, 818-830. doi: 10.1016/j.cell.2012.12.043

Hammes, W. P., and Hertel, C. (2015). "Lactobacillus," in Bergey's Manual of Systematics of Archaea and Bacteria, ed. W. B. Whitman (Hoboken, NJ: John Wiley \& Sons), 1-76. doi: 10.1002/9781118960608.gbm00604

Han, X., Mann, E., Gilbert, S., Guan, Y., Steinbrecher, K. A., Montrose, M. H., et al. (2011). Loss of guanylyl cyclase C (GCC) signaling leads to dysfunctional intestinal barrier. PLoS ONE 6:e16139. doi: 10.1371/journal.pone.0016139

Hannig, G., Tchernychev, B., Kurtz, C. B., Bryant, A. P., Currie, M. G., and SilosSantiago, I. (2014). Guanylate cyclase-C/cGMP: an emerging pathway in the regulation of visceral pain. Front. Mol. Neurosci. 7:31. doi: 10.3389/fnmol.2014. 00031

Harmsen, H. J., Raangs, G. C., He, T., Degener, J. E., and Welling, G. W. (2002). Extensive set of 16S rRNA-based probes for detection of bacteria in human feces. Appl. Environ. Microbiol. 68, 2982-2990. doi: 10.1128/AEM.68.6.29822990.2002

Haro, C., Rangel-Zuniga, O. A., Alcala-Diaz, J. F., Gomez-Delgado, F., PerezMartinez, P., Delgado-Lista, J., et al. (2016). Intestinal microbiota is influenced by gender and body mass index. PLoS ONE 11:e0154090. doi: 10.1371/journal. pone. 0154090

Hayes, M., Stanton, C., Slattery, H., O’Sullivan, O., Hill, C., Fitzgerald, G. F., et al. (2007). Casein fermentate of Lactobacillus animalis DPC6134 contains a range of novel propeptide angiotensin-converting enzyme inhibitors. Appl. Environ. Microbiol. 73, 4658-4667. doi: 10.1128/AEM.00096-07

Hertzberger, R., Arents, J., Dekker, H. L., Pridmore, R. D., Gysler, C., Kleerebezem, M., et al. (2014). $\mathrm{H}_{2} \mathrm{O}_{2}$ production in species of the Lactobacillus acidophilus group: a central role for a novel NADH-dependent flavin reductase. Appl. Environ. Microbiol. 80, 2229-2239. doi: 10.1128/AEM.04272-13

Holden, J. K., Kang, S., Hollingsworth, S. A., Li, H., Lim, N., Chen, S., et al. (2015). Structure-based design of bacterial nitric oxide synthase inhibitors. J. Med. Chem. 58, 994-1004. doi: 10.1021/jm501723p

Hong, H. A., To, E., Fakhry, S., Baccigalupi, L., Ricca, E., and Cutting, S. M. (2009). Defining the natural habitat of Bacillus spore-formers. Res. Microbiol. 160, 375-379. doi: 10.1016/j.resmic.2009.06.006

Huang, X., Lu, Z., and Yang, S. (2006). Antiviral activity of antimicrobial lipopeptide from Bacillus subtilis fmbj against pseudorabies virus, porcine parvovirus, newcastle disease virus and infectious bursal disease virus in vitro. Int. J. Pept. Res. Ther. 12, 373-377. doi: 10.1007/s10989-006-9041-4

Hyronimus, B., Le Marrec, C., and Urdaci, M. C. (1998). Coagulin, a bacteriocinlike inhibitory substance produced by Bacillus coagulans I4. J. Appl. Microbiol. 85, 42-50. doi: 10.1046/j.1365-2672.1998.00466.x

Iarullina, D. R., and Ilinskaia, O. N. (2007). Genomic determinants of nitric oxide biosynthesis by Lactobacillus plantarum: potential opportunities and reality. Mol. Biol. 41, 900-907. doi: 10.1134/S0026893307050159

Iarullina, D. R., Ilinskaia, O. N., Aganov, A. V., Silkin, N. I., and Zverev, D. G. (2006). Alternative pathways of nitric oxide formation in lactobacilli: EPR evidence for nitric oxide synthase activity. Mikrobiologiia 75, 731-736. doi: 10.1134/S0026261706060026

Ilinskaya, O. N., and Shah Mahmud, R. (2014). Ribonucleases as antiviral agents. Mol. Biol. 48, 707-717. doi: 10.1134/S0026893314040050

Ilinskaya, O. N., Singh, I., Dudkina, E., Ulyanova, V., Kayumov, A., and Barreto, G. (2016). Direct inhibition of oncogenic KRAS by Bacillus pumilus ribonuclease (binase). Biochim. Biophys. Acta 1863, 1559-1567. doi: 10.1016/j.bbamcr.2016. 04.005 
Imlay, J. A. (2003). Pathways of oxidative damage. Annu. Rev. Microbiol. 57, 395-418. doi: 10.1146/annurev.micro.57.030502.090938

Jackson, E. K., Cheng, D., Jackson, T. C., Verrier, J. D., and Gillespie, D. G. (2013). Extracellular guanosine regulates extracellular adenosine levels. Am. J. Physiol. Cell Physiol. 304, C406-C421. doi: 10.1152/ajpcell.00212.2012

Jandhyala, S. M., Talukdar, R., Subramanyam, C., Vuyyuru, H., Sasikala, M., and Reddy, D. N. (2015). Role of the normal gut microbiota. World J. Gastroenterol. 21, 8787-8803. doi: 10.3748/wjg.v21.i29.8787

Jung, T. H., Park, J. H., Jeon, W. M., and Han, K. S. (2015). Butyrate modulates bacterial adherence on LS174T human colorectal cells by stimulating mucin secretion and MAPK signaling pathway. Nutr. Res. Pract. 9, 343-349. doi: $10.4162 / \mathrm{nrp} .2015 .9 .4 .343$

Kaškonienè, V., Stankevičius, M., Bimbiraitè-Survilienè, K., Naujokaityte, G., Šerniené, L., Mulkyte, K., et al. (2017). Current state of purification, isolation and analysis of bacteriocins produced by lactic acid bacteria. Appl. Microbiol. Biotechnol. 101, 1323-1335. doi: 10.1007/s00253-017-8088-9

Keller, D., Van Dinter, R., Cash, H., Farmer, S., and Venema, K. (2017). Bacillus coagulans GBI-30, 6086 increases plant protein digestion in a dynamic, computer-controlled in vitro model of the small intestine (TIM-1). Benef. Microbes 8, 491-496. doi: 10.3920/BM2016.0196

Khochamit, N., Siripornadulsil, S., Sukon, P., and Siripornadulsil, W. (2015). Antibacterial activity and genotypic-phenotypic characteristics of bacteriocinproducing Bacillus subtilis KKU213: potential as a probiotic strain. Microbiol. Res. 170, 36-50. doi: 10.1016/j.micres.2014.09.004

Kim, Y., Edwards, N., and Fenselau, C. (2016). Extracellular vesicle proteomes reflect developmental phases of Bacillus subtilis. Clin. Proteomics 13, 6. doi: 10.1186/s12014-016-9107-z

Kinkel, T. L., Ramos-Montañez, S., Pando, J. M., Tadeo, D. V., Strom, E. N., Libby, S. J., et al. (2016). An essential role for bacterial nitric oxide synthase in Staphylococcus aureus electron transfer and colonization. Nat. Microbiol. 2:16224. doi: 10.1038/nmicrobiol.2016.224

Konishi, H., Fujiya, M., Tanaka, H., Ueno, N., Moriichi, K., Sasajima, J., et al. (2016). Probiotic-derived ferrichrome inhibits colon cancer progression via JNK-mediated apoptosis. Nat. Commun. 7:12365. doi: 10.1038/ncomms 12365

Kumar, R., Grover, S., and Batish, V. K. (2012). Bile salt hydrolase (Bsh) activity screening of lactobacilli: in vitro selection of indigenous Lactobacillus strains with potential bile salt hydrolysing and cholesterol-lowering ability. Probiotics Antimicrob. Proteins 4, 162-172. doi: 10.1007/s12602-012-9101-3

Lagier, J. C., Hugon, P., Khelaifia, S., Fournier, P. E., La Scola, B., and Raoult, D. (2015). The rebirth of culture in microbiology through the example of culturomics to study human gut microbiota. Clin. Microbiol. Rev. 28, 237-264. doi: 10.1128/CMR.00014-14

Lagier, J. C., Khelaifia, S., Alou, M. T., Ndongo, S., Dione, N., Hugon, P., et al. (2016). Culture of previously uncultured members of the human gut microbiota by culturomics. Nat. Microbiol. 1:16203. doi: 10.1038/nmicrobiol.2016.203

Lahtinen, S. J. (2012). Probiotic viability - does it matter? Microb. Ecol. Health Dis. 23, 10-14. doi: 10.3402/mehd.v23i0.18567

Lamas, B., Richard, M. L., Leducq, V., Pham, H. P., Michel, M. L., Da Costa, G., et al. (2016). CARD9 impacts colitis by altering gut microbiota metabolism of tryptophan into aryl hydrocarbon receptor ligands. Nat. Med. 22, 598-605. doi: $10.1038 / \mathrm{nm} .4102$

Lan, D., Niu, J., Miao, J., Dong, X., Wang, H., Yang, G., et al. (2016). Expression of guanylate cyclase-C, guanylin, and uroguanylin is downregulated proportionally to the ulcerative colitis disease activity index. Sci. Rep. 6:25034. doi: 10.1038/srep25034

LeBlanc, J. G., Chain, F., Martín, R., Bermúdez-Humarán, L. G., Courau, S., and Langella, P. (2017). Beneficial effects on host energy metabolism of shortchain fatty acids and vitamins produced by commensal and probiotic bacteria. Microb. Cell Fact. 16, 79. doi: 10.1186/s12934-017-0691-z

Lee, M. H., Lee, J., Nam, Y. D., Lee, J. S., Seo, M. J., and Yi, S. H. (2016). Characterization of antimicrobial lipopeptides produced by Bacillus sp. LM7 isolated from chungkookjang, a Korean traditional fermented soybean food. Int. J. Food Microbiol. 221, 12-18. doi: 10.1016/j.ijfoodmicro.2015.12.010

Li, M., Lee, K., Hsu, M., Nau, G., Mylonakis, E., and Ramratnam, B. (2017). Lactobacillus-derived extracellular vesicles enhance host immune responses against vancomycin-resistant enterococci. BMC Microbiol. 17:66. doi: 10.1186/ s12866-017-0977-7
Lim, K. B., Balolong, M. P., Kim, S. H., Oh, J. K., Lee, J. Y., and Kang, D. K. (2016). Isolation and characterization of a broad spectrum bacteriocin from Bacillus amyloliquefaciens RX7. Biomed Res. Int. 2016:8521476. doi: 10.1155/ 2016/8521476

Lin, J. E., Snook, A. E., Li, P., Stoecker, B. A., Kim, G. W., Magee, M. S., et al. (2012). GUCY2C opposes systemic genotoxic tumorigenesis by regulating AKT-dependent intestinal barrier integrity. PLoS ONE 7:e31686. doi: 10.1371/ journal.pone. 0031686

Liu, G., Kong, Y., Fan, Y., Geng, C., Peng, D., and Sun, M. (2017). Whole-genome sequencing of Bacillus velezensis LS69, a strain with a broad inhibitory spectrum against pathogenic bacteria. J. Biotechnol. 249, 20-24. doi: 10.1016/j.jbiotec. 2017.03.018

Liu, S., and Weiner, H. L. (2016). Control of the gut microbiome by fecal microRNA. Microb. Cell 3, 176-177. doi: 10.15698/mic2016.04.492

Lopetuso, L. R., Scaldaferri, F., Franceschi, F., and Gasbarrini, A. (2016). Bacillus clausii and gut homeostasis: state of the art and future perspectives. Expert Rev. Gastroenterol. Hepatol. 10, 943-948. doi: 10.1080/17474124.2016. 1200465

Luber, J. M., and Kostic, A. D. (2017). Gut microbiota: small molecules modulate host cellular functions. Curr. Biol. 27, R307-R310. doi: 10.1016/j.cub.2017. 03.026

Maffei, V. J., Kim, S., Blanchard, E., Luo, M., Jazwinski, S. M.,Taylor, C. M., et al. (2017). Biological aging and the human gut microbiota. J. Gerontol. A Biol. Sci. Med. Sci. doi: 10.1093/gerona/glx042 [Epub ahead of print].

Magnúsdóttir, S., Ravcheev, D., de Crécy-Lagard, V., and Thiele, I. (2015). Systematic genome assessment of B-vitamin biosynthesis suggests co-operation among gut microbes. Front. Genet. 6:148. doi: 10.3389/fgene.2015.00148

Majeed, M., Nagabhushanam, K., Natarajan, S., Sivakumar, A., Ali, F., Pande, A., et al. (2016). Bacillus coagulans MTCC 5856 supplementation in the management of diarrhea predominant Irritable Bowel Syndrome: a double blind randomized placebo controlled pilot clinical study. Nutr. J. 15, 21. doi: 10.1186/s12937-016-0140-6

Marchesi, J. R., Adams, D. H., Fava, F., Hermes, G. D., Hirschfield, G. M., Hold, G., et al. (2016). The gut microbiota and host health: a new clinical frontier. Gut 65, 330-339. doi: 10.1136/gutjnl-2015-309990

Marco, M. L., Heeney, D., Binda, S., Cifelli, C. J., Cotter, P. D., Foligné, B., et al. (2017). Health benefits of fermented foods: microbiota and beyond. Curr. Opin. Biotechnol. 44, 94-102. doi: 10.1016/j.copbio.2016.11.010

Mariat, D., Firmesse, O., Levenez, F., Guimarăes, V., Sokol, H., Doré, J., et al. (2009). The Firmicutes/Bacteroidetes ratio of the human microbiota changes with age. BMC Microbiol. 9:123. doi: 10.1186/1471-2180-9-123

Martí, J. M., Martínez-Martínez, D., Rubio, T., Gracia, C., Peña, M., Latorre, A., et al. (2017). Health and disease imprinted in the time variability of the human microbiome. mSystems 2:e00144-16. doi: 10.1128/mSystems.00144-16

Martín, R., and Suárez, J. E. (2010). Biosynthesis and degradation of $\mathrm{H}_{2} \mathrm{O}_{2}$ by vaginal lactobacilli. Appl. Environ. Microbiol. 76, 400-405. doi: 10.1128/AEM. 01631-09

Martinez, R. C., Wachsman, M., Torres, N. I., LeBlanc, J. G., Todorov, S. D., and Franco, B. D. (2013). Biochemical, antimicrobial and molecular characterization of a noncytotoxic bacteriocin produced by Lactobacillus plantarum ST71KS. Food Microbiol. 34, 376-381. doi: 10.1016/j.fm.2013.01.011

Mashburn, L. M., and Whiteley, M. (2005). Membrane vesicles traffic signals and facilitate group activities in a prokaryote. Nature 437, 422-425. doi: 10.1038/ nature 03925

Matsuda, K., Tsuji, H., Asahara, T., Matsumoto, K., Takada, T., and Nomoto, K. (2009). Establishment of an analytical system for the human fecal microbiota, based on reverse transcription-quantitative PCR targeting of multicopy rRNA molecules. Appl. Environ. Microbiol. 75, 1961-1969. doi: 10.1128/AEM.01 843-08

Matsuoka, K., and Kanai, T. (2015). The gut microbiota and inflammatory bowel disease. Semin. Immunopathol. 37, 47-55. doi: 10.1007/s00281-014-0454-4

McKay, K. A., Kowalec, K., Brinkman, F., Finlay, B. B., Horwitz, M., Manges, A. R., et al. (2017). From bugs to brains: the microbiome in neurological health. Mult. Scler. Relat. Disord. 12, 1-3. doi: 10.1016/j.msard.2016.12.007

Midha, S., Mishra, R., Aziz, M. A., Sharma, M., Mishra, A., Khandelwal, P., et al. (2005). Cloning, expression and characterization of recombinant nitric oxide synthase-like protein from Bacillus anthracis. Biochem. Biophys. Res. Commun. 336, 346-356. doi: 10.1016/j.bbrc.2005.08.083 
Mitkevich, V. A., Kretova, O. V., Petrushanko, I. Y., Burnysheva, K. M., Sosin, D. V., Simonenko, O. V., et al. (2013). Ribonuclease binase apoptotic signature in leukemic Kasumi-1 cells. Biochimie 95, 1344-1349. doi: 10.1016/j.biochi. 2013.02.016

Morita, H., Yoshikawa, H., Sakata, R., Nagata, Y., and Tanaka, H. (1997). Synthesis of nitric oxide from the two equivalent guanidino nitrogens of $\mathrm{L}$-arginine by Lactobacillus fermentum. J. Bacteriol. 179, 7812-7815. doi: 10.1128/jb.179.24. 7812-7815.1997

Mourembou, G., Ndjoyi-Mbiguino, A., Lekana-Douki, J. B., Fournier, P. E., Raoult, D., and Bittar, F. (2016). Discovery of a new species within Bacillus genus in a stool sample from Gabon: "Bacillus massiliogabonensis" sp. nov. New Microbes New Infect. 15, 3-5. doi: 10.1016/j.nmni.2016.09.013

Müller, C., Ulyanova, V., Ilinskaya, O., Pleschka, S., and Shah Mahmud, R. (2017). A novel antiviral strategy against MERS-CoV and HCoV-229E using binase to target viral genome replication. BioNanoScience 7, 294-299. doi: 10.1007/ s12668-016-0341-7

Müller, S., Strack, S. N., Hoefler, B. C., Straight, P. D., Kearns, D. B., and Kirby, J. R. (2014). Bacillaene and sporulation protect Bacillus subtilis from predation by Myxococcus xanthus. Appl. Environ. Microbiol. 80, 5603-5610. doi: 10.1128/ AEM.01621-14

Nakamura, K., Sakuragi, N., Takakuwa, A., and Ayabe, T. (2016). Paneth cell $\alpha$-defensins and enteric microbiota in health and disease. Biosci. Microbiota Food Health 35, 57-67. doi: 10.12938/bmfh.2015-019

Natarajan, N., and Pluznick, J. L. (2014). From microbe to man: the role of microbial short chain fatty acid metabolites in host cell biology. Am. J. Physiol. Cell Physiol. 307, C979-C985. doi: 10.1152/ajpcell.00228.2014

Nava, G. M., and Stappenbeck, T. S. (2011). Diversity of the autochthonous colonic microbiota. Gut Microbes 2, 99-104. doi: 10.4161/gmic.2.2.15416

Nguyen, U. T., and Burrows, L. L. (2014). DNase I and proteinase K impair Listeria monocytogenes biofilm formation and induce dispersal of pre-existing biofilms. Int. J. Food Microbiol. 187, 26-32. doi: 10.1016/j.ijfoodmicro.2014.06.025

Nithya, V., Muthukumar, S. P., and Halami, P. M. (2012). Safety assessment of Bacillus licheniformis $\mathrm{Me} 1$ isolated from milk for probiotic application. Int. J. Toxicol. 31, 228-237. doi: 10.1177/1091581812443388

Nøhr, M. K., Egerod, K. L., Christiansen, S. H., Gille, A., Offermanns, S., Schwartz, T. W., et al. (2015). Expression of the short chain fatty acid receptor GPR41/FFAR3 in autonomic and somatic sensory ganglia. Neuroscience 290, 126-137. doi: 10.1016/j.neuroscience.2015.01.040

Nyangale, E. P., Farmer, S., Cash, H. A., Keller, D., Chernoff, D., and Gibson, G. R. (2015). Bacillus coagulans GBI-30, 6086 modulates Faecalibacterium prausnitzii in older men and women. J. Nutr. 145, 1446-1452. doi: 10.3945/jn.114.199802

Odamaki, T., Kato, K., Sugahara, H., Hashikura, N., Takahashi, S., Xiao, J. Z., et al. (2016). Age-related changes in gut microbiota composition from newborn to centenarian: a cross-sectional study. BMC Microbiol. 16:90. doi: 10.1186/ s12866-016-0708-5

Okamoto, K., Fujiya, M., Nata, T., Ueno, N., Inaba, Y., Ishikawa, C., et al. (2012). Competence and sporulation factor derived from Bacillus subtilis improves epithelial cell injury in intestinal inflammation via immunomodulation and cytoprotection. Int. J. Colorectal Dis. 27, 1039-1046. doi: 10.1007/s00384-0121416-8

Oscariz, J. C., and Pisabarro, A. G. (2001). Classification and mode of action of membrane-active bacteriocins produced by gram-positive bacteria. Int Microbiol. 4, 13-19.

Ott, S. J., Musfeldt, M., Wenderoth, D. F., Hampe, J., Brant, O., Fölsch, U. R., et al. (2004). Reduction in diversity of the colonic mucosa associated bacterial microflora in patients with active inflammatory bowel disease. Gut 53, 685-693. doi: 10.1136/gut.2003.025403

Panda, S., El khader, I., Casellas, F., López Vivancos, J., García Cors, M., Santiago, A., et al. (2014). Short-term effect of antibiotics on human gut microbiota. PLoS ONE 9:e95476. doi: 10.1371/journal.pone.0095476

Patel, A. K., Singhania, R. R., Pandey, A., and Chincholakar, S. B. (2010). Probiotic bile salt hydrolase: current development and perspectives. Appl. Biochem. Biotechnol. 162, 166-180. doi: 10.1007/s12010-009-8738-1

Pattison, A. M., Merlino, D. J., Blomain, E. S., and Waldman, S. A. (2016). Guanylyl cyclase $\mathrm{C}$ signaling axis and colon cancer prevention. World J. Gastroenterol. 22, 8070-8077. doi: 10.3748/wjg.v22.i36.8070

Peng, L., Li, Z. R., Green, R. S., Holzman, I. R., and Lin, J. (2009). Butyrate enhances the intestinal barrier by facilitating tight junction assembly via activation of
AMP-activated protein kinase in Caco-2 cell monolayers. J. Nutr. 139, 16191625. doi: 10.3945/jn.109.104638

Perez, K. J., Viana, J. D., Lopes, F. C., Pereira, J. Q., Dos Santos, D. M., Oliveira, J. S., et al. (2017). Bacillus spp. isolated from puba as a source of biosurfactants and antimicrobial lipopeptides. Front. Microbiol. 8:61. doi: 10.3389/fmicb.2017. 00061

Pillai, A., and Nelson, R. (2008). Probiotics for treatment of Clostridium difficileassociated colitis in adults. Cochrane Database Syst. Rev. 23, CD004611. doi: 10.1002/14651858.CD004611.pub2

Pridmore, R. D., Pittet, A. C., Praplan, F., and Cavadini, C. (2008). Hydrogen peroxide production by Lactobacillus johnsonii NCC 533 and its role in antiSalmonella activity. FEMS Microbiol. Lett. 283, 210-215. doi: 10.1111/j.15746968.2008.01176.x

Prior, I. A., Lewis, P. D., and Mattos, C. (2012). A comprehensive survey of Ras mutations in cancer. Cancer Res. 72, 2457-2467. doi: 10.1158/0008-5472.CAN11-2612

Quagliariello, A., Aloisio, I., Bozzi Cionci, N., Luiselli, D., D’Auria, G., MartinezPriego, L., et al. (2016). Effect of Bifidobacterium breve on the intestinal microbiota of coeliac children on a gluten free diet: a pilot study. Nutrients 8:660. doi: 10.3390/nu8100660

Rafter, J., Bennett, M., Caderni, G., Clune, Y., Hughes, R., Karlsson, P. C., et al. (2007). Dietary synbiotics reduce cancer risk factors in polypectomized and colon cancer patients. Am. J. Clin. Nutr. 85, 488-496.

Rajilić-Stojanović, M., and de Vos, W. M. (2014). The first 1000 cultured species of the human gastrointestinal microbiota. FEMS Microbiol. Rev. 38, 996-1047. doi: 10.1111/1574-6976.12075

Rapozo, D. C., Bernardazzi, C., and de Souza, H. S. (2017). Diet and microbiota in inflammatory bowel disease: the gut in disharmony. World J. Gastroenterol. 23, 2124-2140. doi: 10.3748/wjg.v23.i12.2124

Reuter, G. (2001). The Lactobacillus and Bifidobacterium microflora of the human intestine: composition and succession. Curr. Issues Intest. Microbiol. 2, 43-53.

Rey, M. W., Ramaiya, P., Nelson, B. A., Brody-Karpin, S. D., Zaretsky, E. J., Tang, M., et al. (2004). Complete genome sequence of the industrial bacterium Bacillus licheniformis and comparisons with closely related Bacillus species. Genome Biol. 5:R77. doi: 10.1186/gb-2004-5-10-r77

Rhee, K. J., Sethupathi, P., Driks, A., Lanning, D. K., and Knight, K. L. (2004). Role of commensal bacteria in development of gut-associated lymphoid tissues and preimmune antibody repertoire. J. Immunol. 172, 1118-1124. doi: 10.4049/ jimmunol.172.2.1118

Ríos-Covián, D., Ruas-Madiedo, P., Margolles, A., Gueimonde, M., de Los ReyesGavilán, C. G., and Salazar, N. (2016). Intestinal short chain fatty acids and their link with diet and human health. Front. Microbiol. 7:185. doi: 10.3389/fmicb. 2016.00185

Rivera, J., Cordero, R. J., Nakouzi, A. S., Frases, S., Nicola, A., and Casadevall, A. (2010). Bacillus anthracis produces membrane-derived vesicles containing biologically active toxins. Proc. Natl. Acad. Sci. U.S.A. 107, 19002-19007. doi: $10.1073 /$ pnas. 1008843107

Roier, S., Zingl, F. G., Cakar, F., and Schild, S. (2016). Bacterial outer membrane vesicle biogenesis: a new mechanism and its implications. Microb. Cell 3, 257-259. doi: 10.15698/mic2016.06.508

Rowland, I., Gibson, G., Heinken, A., Scott, K., Swann, J., Thiele, I., et al. (2017). Gut microbiota functions: metabolism of nutrients and other food components. Eur. J. Nutr. doi: 10.1007/s00394-017-1445-8 [Epub ahead of print].

Ruiz, L., Hevia, A., Bernardo, D., Margolles, A., and Sanchez, B. (2014). Extracellular molecular effectors mediating probiotic attributes. FEMS Microbiol. Lett. 359, 1-11. doi: 10.1111/1574-6968.12576

Sakatani, A., Fujiya, M., Ueno, N., Kashima, S., Sasajima, J., Moriichi, K., et al. (2016). Polyphosphate derived from Lactobacillus brevis inhibits colon cancer progression through induction of cell apoptosis. Anticancer. Res. 36, 591-598.

Salard, I., Mercey, E., Rekka, E., Boucher, J.-L., Nioche, P., Mikula, I., et al. (2006). Analogies and surprising differences between recombinant nitric oxide synthase-like proteins from Staphylococcus aureus and Bacillus anthracis in their interactions with L-arginine analogs and iron ligands. J. Inorg. Biochem. 100, 2024-2033. doi: 10.1016/j.jinorgbio.2006.09.017

Sandrini, S., Aldriwesh, M., Alruways, M., and Freestone, P. (2015). Microbial endocrinology: host-bacteria communication within the gut microbiome. J. Endocrinol. 225, R21-R34. doi: 10.1530/JOE14-0615 
Sankar, S. A., Lagier, J. C., Pontarotti, P., Raoult, D., and Fournier, P. E. (2015). The human gut microbiome, a taxonomic conundrum. Syst. Appl. Microbiol. 38, 276-286. doi: 10.1016/j.syapm.2015.03.004

Satish Kumar, R., Kanmani, P., Yuvaraj, N., Paari, K. A., Pattukumar, V., and Arul, V. (2013). Traditional Indian fermented foods: a rich source of lactic acid bacteria. Int. J. Food Sci. Nutr. 64, 415-428. doi: 10.3109/09637486.2012.746288

Sazawal, S., Hiremath, G., Dhingra, U., Malik, P., Deb, S., and Black, R. E. (2006). Efficacy of probiotics in prevention of acute diarrhea: a meta-analysis of masked, randomized, placebo-controlled trials. Lancet Infect. Dis. 6, 374-382. doi: 10.1016/S1473-3099(06)70495-9

Segawa, S., Fujiya, M., Konishi, H., Ueno, N., Kobayashi, N., Shigyo, T., et al. (2011). Probiotic-derived polyphosphate enhances the epithelial barrier function and maintains intestinal homeostasis through integrin-p38 MAPK pathway. PLoS ONE 6:e23278. doi: 10.1371/journal.pone.0023278

Selvam, R., Maheswari, P., Kavitha, P., Ravichandran, M., Sas, B., and Ramchand, C. N. (2009). Effect of Bacillus subtilis PB6, a natural probiotic on colon mucosal inflammation and plasma cytokines levels in inflammatory bowel disease. Indian J. Biochem. Biophys. 46, 79-85.

Senghor, B., Seck, E. H., Khelaifia, S., Bassène, H., Sokhna, C., Fournier, P. E., et al. (2017). Description of 'Bacillus dakarensis' sp. nov., 'Bacillus sinesaloumensis' sp. nov., 'Gracilibacillus timonensis' sp. nov., 'Halobacillus massiliensis' sp. nov., 'Lentibacillus massiliensis' sp. nov., 'Oceanobacillus senegalensis' sp. nov., 'Oceanobacillus timonensis' sp. nov., 'Virgibacillus dakarensis' sp. nov. and 'Virgibacillus marseillensis' sp. nov., nine halophilic new species isolated from human stool. New Microbes New Infect. 17, 45-51. doi: 10.1016/j.nmni.2017. 01.010

Servin, A. L. (2004). Antagonistic activities of lactobacilli and bifidobacteria against microbial pathogens. FEMS Microbiol. Rev. 28, 405-440. doi: 10.1016/j.femsre. 2004.01.003

Shah Mahmud, R., Efimova, M., Mostafa, A., Ulyanova, V., and Ilinskaya, O. (2016). Antiviral activity of bacterial extracellular ribonuclease against single-, double stranded RNA and DNA containing viruses in cell cultures. BioNanoScience 6, 561-563. doi: 10.1007/s12668-016-0279-9

Shah Mahmud, R., and Ilinskaya, O. N. (2013). Antiviral activity of binase against the pandemic influenza A (H1N1) virus. Acta Nat. 5, 44-51.

Shah Mahmud, R., Müller, C., Romanova, Y., Mostafa, A., Ulyanova, V., Pleschka, S., et al. (2017). Ribonuclease from Bacillus acts as an antiviral agent against negative- and positive-sense single stranded human respiratory RNA viruses. Biomed Res. Int. 2017:5279065. doi: 10.1155/2017/527 9065

Sharon, G., Sampson, T. R., Geschwind, D. H., and Mazmanian, S. K. (2016). The central nervous system and the gut microbiome. Cell 167, 915-932. doi: 10.1016/j.cell.2016.10.027

Shi, N., Li, N., Duan, X., and Niu, H. (2017). Interaction between the gut microbiome and mucosal immune system. Mil. Med. Res. 4, 14. doi: 10.1186/ s40779-017-0122-9

Shields, R. C., Mokhtar, N., Ford, M., Hall, M. J., Burgess, J. G., ElBadawey, M. R., et al. (2013). Efficacy of a marine bacterial nuclease against biofilm forming microorganisms isolated from chronic rhinosinusitis. PLoS ONE 8:e55339. doi: 10.1371/journal.pone.0055339

Shobharani, P., and Halami, P. M. (2014). Cellular fatty acid profile and $\mathrm{H}^{+}$ATPAse activity to assess acid tolerance of Bacillus sp. for potential probiotic functional attributes. Appl. Microbiol. Biotechnol. 98, 9045-9058. doi: 10.1007/ s00253-014-5981-3

Shobharani, P., Padmaja, R. J., and Halami, P. M. (2015). Diversity in the antibacterial potential of probiotic cultures Bacillus licheniformis MCC2514 and Bacillus licheniformis MCC2512. Res. Microbiol. 166, 546-554. doi: 10.1016/j. resmic.2015.06.003

Shukla, S. D., Budden, K. F., Neal, R., and Hansbro, P. M. (2017). Microbiome effects on immunity, health and disease in the lung. Clin. Transl. Immunol. 6, e133. doi: $10.1038 /$ cti.2017.6

Singh, R. K., Chang, H. W., Yan, D., Lee, K. M., Ucmak, D., Wong, K., et al. (2017). Influence of diet on the gut microbiome and implications for human health. J. Transl. Med. 15, 73. doi: 10.1186/s12967-017-1175-y

Siraj, Y., Nguen, N., Zelenikhin, P. V., Sokolova, E. V., Gataullin, I. G., and Ilinskaya, O. N. (2015). Dysbiosis of cultivable aerobic microbiota tightly associated with colon cancer epithelial cells. RJPBCS 6, 1658-1663.
Smaoui, S., Elleuch, L., Bejar, W., Karray-Rebai, I., Ayadi, I., Jaouadi, B., et al. (2010). Inhibition of fungi and gram-negative bacteria by bacteriocin BacTN635 produced by Lactobacillus plantarum sp. TN635. Appl. Biochem. Biotechnol. 162, 1132-1146. doi: 10.1007/s12010-009-8821-7

Sobke, A., Klinger, M., Hermann, B., Sachse, S., Nietzsche, S., Makarewicz, O., et al. (2012). The urinary antibiotic 5-nitro-8-hydroxyquinoline (Nitroxoline) reduces the formation and induces the dispersal of Pseudomonas aeruginosa biofilms by chelation of iron and zinc. Antimicrob. Agents Chemother. 56, 6021-6025. doi: 10.1128/AAC.01484-12

Sokurenko, J. V., Zelenikhin, P. V., Ulyanova, V. V., Kolpakov, A. I., Muler, D., and Ilinskaya, O. N. (2015). Identification of 2,3' $3^{\prime}$-cGMP as an intermediate of RNA catalytic cleavage by binase and evaluation of its biological action. Russ. J. Bioorg. Chem. 41, 31-36. doi: 10.1134/S1068162015010136

Sornplang, P., and Piyadeatsoontorn, S. (2016). Probiotic isolates from unconventional sources: a review. J. Anim. Sci. Technol. 58, 26. doi: 10.1186/ s40781-016-0108-2

Stern, N. J., Svetoch, E. A., Eruslanov, B. V., Perelygin, V. V., Mitsevich, E. V., Mitsevich, I. P., et al. (2006). Isolation of a Lactobacillus salivarius strain and purification of its bacteriocin, which is inhibitory to Campylobacter jejuni in the chicken gastrointestinal system. Antimicrob. Agents Chemother. 50, 3111-3116. doi: 10.1128/AAC.00259-06

Stubbendieck, R. M., and Straight, P. D. (2016). Multifaceted interfaces of bacterial competition. J. Bacteriol. 198, 2145-2155. doi: 10.1128/JB.00275- 16

Sudhamsu, J., and Crane, B. R. (2006). Structure and reactivity of a thermostable prokaryotic nitric-oxide synthase that forms a long-lived oxy-heme complex. J. Biol. Chem. 281, 9623-9632. doi: 10.1074/jbc.M510062200

Sumi, C. D., Yang, B. W., Yeo, I. C., and Hahm, Y. T. (2015). Antimicrobial peptides of the genus Bacillus: a new era for antibiotics. Can. J. Microbiol. 61, 93-103. doi: 10.1139/cjm-2014-0613

Tam, N. K., Uyen, N. Q., Hong, H. A., Duc, L. H., Hoa, T. T., Serra, C. R., et al. (2006). The intestinal life cycle of Bacillus subtilis and close relatives. J. Bacteriol. 188, 2692-2700. doi: 10.1128/JB.188.7.2692-2700.2006

Tamang, J. P., Shin, D. H., Jung, S. J., and Chae, S. W. (2016). Functional properties of microorganisms in fermented foods. Front. Microbiol. 7:578. doi: 10.3389/ fmicb.2016.00578

Tang, W. H., Kitai, T., and Hazen, S. L. (2017). Gut microbiota in cardiovascular health and disease. Circ. Res. 120, 1183-1196. doi: 10.1161/CIRCRESAHA.117. 309715

Thomas, C., and Versalovic, J. (2010). Probiotics-host communication: modulation of signaling pathways in the intestine. Gut Microbes 1, 148-163. doi: 10.4161/ gmic.1.3.11712

Travers, M. A., Sow, C., Zirah, S., Deregnaucourt, C., Chaouch, S., Queiroz, R. M., et al. (2016). Deconjugated bile salts produced by extracellular bile-salt hydrolase-like activities from the probiotic Lactobacillus johnsonii La1 inhibit Giardia duodenalis in vitro growth. Front. Microbiol. 7:1453. doi: 10.3389/ fmicb.2016.01453

Tropini, C., Earle, K. A., Huang, K. C., and Sonnenburg, J. L. (2017). The Gut microbiome: connecting spatial organization to function. Cell Host Microbe 21, 433-442. doi: 10.1016/j.chom.2017.03.010

Tsilingiri, K., and Rescigno, M. (2013). Postbiotics: What else? Benef. Microbes 4, 101-107. doi: 10.3920/BM2012.0046

Ulyanova, V., Shah Mahmud, R., Dudkina, E., Vershinina, V., Domann, E., and Ilinskaya, O. (2016). Phylogenetic distribution of extracellular guanylpreferring ribonucleases renews taxonomic status of two Bacillus strains. J. Gen. Appl. Microbiol. 62, 181-188. doi: 10.2323/jgam.2016.02.005

Ulyanova, V., Vershinina, V., and Ilinskaya, O. (2011). Barnase and binase: twins with distinct fates. FEBS J. 278, 3633-3643. doi: 10.1111/j.1742-4658.2011. 08294.x

Urgesi, R., Casale, C., Pistelli, R., Rapaccini, G. L., and de Vitis, I. (2014). A randomized double-blind placebo-controlled clinical trial on efficacy and safety of association of simethicone and Bacillus coagulans (Colinox ${ }^{\circledR}$ ) in patients with irritable bowel syndrome. Eur. Rev. Med. Pharmacol. Sci. 18, 1344-1353.

Valko, M., Morris, H., and Cronin, M. T. (2005). Metals, toxicity and oxidative stress. Curr. Med. Chem. 12, 1161-1208. doi: 10.2174/0929867053764635

Valladares, R., Bojilova, L., Potts, A. H., Cameron, E., Gardner, C., Lorca, G., et al. (2013). Lactobacillus johnsonii inhibits indoleamine 2,3-dioxygenase and 
alters tryptophan metabolite levels in BioBreeding rats. FASEB J. 27, 1711-1720. doi: 10.1096/fj.12-223339

Van De Guchte, M., Ehrlich, S. D., and Maguin, E. (2001). Production of growthinhibiting factors by Lactobacillus delbrueckii. J. Appl. Microbiol. 91, 147-153. doi: 10.1046/j.1365-2672.2001.01369.x

van de Wouw, M., Schellekens, H., Dinan, T. G., and Cryan, J. F. (2017). Microbiota-gut-brain axis: modulator of host metabolism and appetite. J. Nutr. 147, 727-745. doi: 10.3945/jn.116.240481

Vanhoutte, T., Huys, G., De Brandt, E., and Swings, J. (2004). Temporal stability analysis of the microbiota in human feces by denaturing gradient gel electrophoresis using universal and group-specific 16S rRNA gene primers. FEMS Microbiol. Ecol. 48, 437-446. doi: 10.1016/j.femsec.2004.03.001

Vargas, G., Rocha, J. D., Oliveira, D. L., Albuquerque, P. C., Frases, S., Santos, S. S., et al. (2015). Compositional and immunobiological analyses of extracellular vesicles released by Candida albicans. Cell. Microbiol. 17, 389-407. doi: 10.1111/ cmi. 12374

Vinoj, G., Vaseeharan, B., Thomas, S., Spiers, A. J., and Shanthi, S. (2014). Quorum-quenching activity of the AHL-lactonase from Bacillus licheniformis DAHB1 inhibits Vibrio biofilm formation in vitro and reduces shrimp intestinal colonisation and mortality. Mar. Biotechnol. 16, 707-715. doi: 10.1007/s10126014-9585-9

Voltan, S., Martines, D., Elli, M., Brun, P., Longo, S., Porzionato, A., et al. (2008). Lactobacillus crispatus $\mathrm{M} 247$-derived $\mathrm{H}_{2} \mathrm{O}_{2}$ acts as a signal transducing molecule activating peroxisome proliferator activated receptor-gamma in the intestinal mucosa. Gastroenterology 135, 1216-1227. doi: 10.1053/j.gastro.2008. 07.007

Vuong, H. E., Yano, J. M., Fung, T. C., and Hsiao, E. Y. (2017). The microbiome and host behavior. Annu. Rev. Neurosci. 40, 21-49. doi: 10.1146/annurev-neuro072116-031347

Walter, J. (2008). Ecological role of lactobacilli in the gastrointestinal tract: implications for fundamental and biomedical research. Appl. Environ. Microbiol. 74, 4985-4996. doi: 10.1128/AEM.00753-08

Walter, J., Hertel, C., Tannock, G. W., Lis, C. M., Munro, K., and Hammes, W. P. (2001). Detection of Lactobacillus, Pediococcus, Leuconostoc, and Weissella species in human feces by using group-specific PCR primers and denaturing gradient gel electrophoresis. Appl. Environ. Microbiol. 67, 2578-2585. doi: 10. 1128/AEM.67.6.2578-2585.2001

Wang, Q., Zhao, X., Chamu, J., and Shanmugam, K. T. (2011). Isolation, characterization and evolution of a new thermophilic Bacillus licheniformis for lactic acid production in mineral salts medium. Bioresour. Technol. 102, 8152-8158. doi: 10.1016/j.biortech.2011.06.003

Wang, R., Islam, B. N., Bridges, A., Sharman, S. K., Hu, M., Hou, Y., et al. (2017). cGMP signaling increases antioxidant gene expression by activating forkhead box O3A in the colon epithelium. Am. J. Pathol. 187, 377-389. doi: 10.1016/j. ajpath.2016.10.016

Watters, C. M., Burton, T., Kirui, D. K., and Millenbaugh, N. J. (2016). Enzymatic degradation of in vitro Staphylococcus aureus biofilms supplemented with human plasma. Infect. Drug Resist. 9, 71-78. doi: 10.2147/IDR.S103101

Wilks, M., Wiggins, R., Whiley, A., Hennessy, E., Warwick, S., Porter, H., et al. (2004). Identification and $\mathrm{H}_{2} \mathrm{O}_{2}$ production of vaginal lactobacilli from pregnant women at high risk of preterm birth and relation with outcome. J. Clin. Microbiol. 42, 713-717. doi: 10.1128/JCM.42.2.713-717.2004

Winek, K., Dirnagl, U., and Meisel, A. (2016). The gut microbiome as therapeutic target in central nervous system diseases: implications for stroke. Neurotherapeutics 13, 762-774. doi: 10.1007/s13311-016-0475-x

Yan, F., Cao, H., Cover, T. L., Whitehead, R., Washington, M. K., and Polk, D. B. (2007). Soluble proteins produced by probiotic bacteria regulate intestinal epithelial cell survival and growth. Gastroenterology 132, 562-575. doi: 10.1053/ j.gastro.2006.11.022

Yan, F., and Polk, D. B. (2002). Probiotic bacterium prevents cytokine-induced apoptosis in intestinal epithelial cells. J. Biol. Chem. 277, 50959-50965. doi: $10.1074 /$ jbc.M207050200

Yan, J., Herzog, J. W., Tsang, K., Brennan, C. A., Bower, M. A., Garrett, W. S., et al. (2016). Gut microbiota induce IGF-1 and promote bone formation and growth. Proc. Natl. Acad. Sci. U.S.A. 113, E7554-E7563. doi: 10.1073/pnas.1607 235113

Yang, M., Jang, I. T., Kim, H. J., and Park, J. K. (2016). Bacillus spp. or Bacillus spp.-derived membrane vesicles induce the intrinsic pathways of apoptosis of human colon cancer cell lines. J. Bacteriol. Virol. 46, 84-92. doi: $10.4167 /$ jbv.2016.46.2.84

Yang, N. J., and Chiu, I. M. (2017). Bacterial signaling to the nervous system through toxins and metabolites. J. Mol. Biol. 429, 587-605. doi: 10.1016/j.jmb. 2016.12.023

Yang, Y., and Jobin, C. (2014). Microbial imbalance and intestinal pathologies: connections and contributions. Dis. Model Mech. 7, 1131-1142. doi: 10.1242/ dmm.016428

Yarullina, D. R., Beuerlein, K., Silkin, N. I., and Ilinskaya, O. N. (2015). Nitric oxide production in probiotic Lactobacillus plantarum: revision of the origin. JMRR 1, 5-14.

Yarullina, D. R., Mikheeva, R. O., Sabirullina, G. I., Zelenikhin, P. V., Ilinskaya, O. N., and Sitdikova, G. F. (2016). Role of nitric oxide produced by lactobacilli in relaxation of intestinal smooth muscles. Bull. Exp. Biol. Med. 160, 343-346. doi: 10.1007/s10517-016-3166-z

Ye, J., Wu, W., Li, Y., and Li, L. (2017). Influences of the gut microbiota on DNA methylation and histone modification. Dig. Dis. Sci. 62, 1155-1164. doi: 10.1007/s10620-017-4538-6

Yunes, R. A., Poluektova, E. U., Dyachkova, M. S., Klimina, K. M., Kovtun, A. S., Averina, O. V., et al. (2016). GABA production and structure of $\mathrm{gadB} / \mathrm{gadC}$ genes in Lactobacillus and Bifidobacterium strains from human microbiota. Anaerobe 42, 197-204. doi: 10.1016/j.anaerobe.2016.10.011

Zacharofa, M. P., and Lovitt, R. W. (2012). Bacteriocins produced by lactic acid bacteria. A review article. APCBEE Proc. 2, 50-56.

Zamfir, M., Callewaert, R., Cornea, P. C., Savu, L., Vatafu, I., and De Vuyst, L. (1999). Purification and characterization of a bacteriocin produced by Lactobacillus acidophilus IBB 801. J. Appl. Microbiol. 87, 923-931. doi: 10.1046/ j.1365-2672.1999.00950.x

Zelante, T., Iannitti Rossana, G., Cunha, C., De Luca, A., Giovannini, G., Pieraccini, G., et al. (2013). Tryptophan catabolites from microbiota engage aryl hydrocarbon receptor and balance mucosal reactivity via interleukin-22. Immunity 39, 372-385. doi: 10.1016/j.immuni.2013. 08.003

Zhang, H. L., Li, W. S., Xu, D. N., Zheng, W. W., Liu, Y., Chen, J., et al. (2016). Mucosa-reparing and microbiota-balancing therapeutic effect of Bacillus subtilis alleviates dextrate sulfate sodium-induced ulcerative colitis in mice. Exp. Ther. Med. 12, 2554-2562. doi: 10.3892/etm.2016.3686

Zhao, X., and Kuipers, O. P. (2016). Identification and classification of known and putative antimicrobial compounds produced by a wide variety of Bacillales species. BMC Genomics 17:882. doi: 10.1186/s12864-0163224-y

Zhou, S., Zhang, A., Yin, H., and Chu, W. (2016). Bacillus sp. QSI-1 modulate quorum sensing signals reduce Aeromonas hydrophila level and alter gut microbial community structure in fish. Front. Cell. Infect. Microbiol. 6:184. doi: 10.3389/fcimb.2016.00184

Zhu, Q., Jin, Z., Wu, W., Gao, R., Guo, B., Gao, Z., et al. (2014). Analysis of the intestinal lumen microbiota in an animal model of colorectal cancer. PLoS ONE 9:e90849. doi: 10.1371/journal.pone.0090849

Conflict of Interest Statement: The authors declare that the research was conducted in the absence of any commercial or financial relationships that could be construed as a potential conflict of interest.

Copyright (C) 2017 Ilinskaya, Ulyanova, Yarullina and Gataullin. This is an openaccess article distributed under the terms of the Creative Commons Attribution License (CC BY). The use, distribution or reproduction in other forums is permitted, provided the original author(s) or licensor are credited and that the original publication in this journal is cited, in accordance with accepted academic practice. No use, distribution or reproduction is permitted which does not comply with these terms. 